\title{
Generation of Custom Acoustic Harmonic Bursts from Spherical Helmholtz Resonators Using Q- Switched Nd:YAG Laser Induced Plasma
}

\section{H Ayoub}

Cairo University

\section{Ashraf El-Sherif}

Military Technical College

Diaa Ibrahim

Egyptian Academy for Engineering and Advanced Technology

\section{ElTahlawy}

Military Technical College

\section{Walid Gomaa}

Military Technical College

Y Nada

Menoufia University

\section{Sana Maize}

Menoufia University

Yahia Elbashar ( $\nabla$ y_elbashar@yahoo.com )

Cairo University https://orcid.org/0000-0002-1362-2189

\section{Research Article}

Keywords: Acoustics harmonic bursts, Spherical Helmholtz resonators, Q-Switched Nd:YAG Laser-induced plasma, AISI 316L stainless steel, Dodecahedron loudspeakers

Posted Date: April 5th, 2021

DOl: https://doi.org/10.21203/rs.3.rs-373841/v1

License: (c) (1) This work is licensed under a Creative Commons Attribution 4.0 International License. Read Full License

Version of Record: A version of this preprint was published at Optical and Quantum Electronics on August 14th, 2021. See the published version at https://doi.org/10.1007/s11082-021-03187-1. 


\title{
Generation of Custom Acoustic Harmonic Bursts from Spherical Helmholtz Resonators Using Q-Switched Nd:YAG Laser Induced Plasma
}

\author{
H. S. Ayoub ${ }^{1,2,3}$, Ashraf F. El-Sherif ${ }^{2}$, Diaa Ibrahim ${ }^{4}$, M. Khairy ElTahlawy ${ }^{2}$, Walid Gomaa ${ }^{2}$, \\ Y. S. Nada ${ }^{3}$, Sana M. A. Maize ${ }^{3}$, Y.H. Elbashar ${ }^{*}$ \\ ${ }^{1}$ Department of Physics, Faculty of Science, Cairo University, Egypt \\ ${ }^{2}$ Engineering Physics Department, Military Technical College, Cairo, Egypt \\ ${ }^{3}$ Department of Physics, Faculty of Science, Menofia University, Egypt \\ ${ }^{4}$ Egyptian Academy for Engineering and Advanced Technology, Egypt \\ ${ }^{5}$ Department of Basic Science, ELGazeera High institute for Engineering and Technology, \\ Cairo, Egypt \\ * Corresponding author: y_elbashar@yahoo.com
}

\begin{abstract}
:
We reported a new method for generating a 4 to $25 \mathrm{~ms}$ high power acoustic harmonic bursts, reaching more than $110 \mathrm{~dB}$ Sound Pressure Level (SPL), from the spherical Helmholtz resonators. The method uses Q-switched Nd:YAG laser pulses (wavelength $=1064 \mathrm{~nm}$, pulse width $=6 \mathrm{~ns}$, and energy $=450 \mathrm{~mJ}$ ) to induce plasma shocks inside an AISI 316L stainless steel cavity. The confined plasma shock produces an acoustic burst of temporal standing waves which are characterized by a wide harmonic bandwidth. The frequency response of the system depends on the geometry of the used Helmholtz resonator as well as the laser wavelength (with constant laser pulse duration and fluence). The experiments reveal the dependence of the odd/even harmonic on laser wavelength. This method is a prospective alternative for the dodecahedron loudspeakers, other sources in ISO and standard audio tests.
\end{abstract}

Keywords: Acoustics harmonic bursts, Spherical Helmholtz resonators, Q-Switched Nd:YAG

Laser-induced plasma, AISI 316L stainless steel, Dodecahedron loudspeakers

\section{Introduction}

One of the challenges in the field of sound measurements and testing is to obtain an omnidirectional, short pulse width and high-power pulsed acoustic source [1]. However, the lower of the pulse width has the harder problem due to the poor frequency selectivity and low sonic/subsonic yield of the acoustic source. For example [2], the fluctuating fluid volume-mass audible sources (like the dynamic speakers, the pressurized gas nozzle injectors, the laser-induced breakdown (LIB), the electric sparks, and the explosive charges) generate a high-intensity sound with a very poor impulse response and/or bad frequency selectivity. Also, the accelerating-fluctuating force on fluid audible sources, where the net volume acceleration equals zero (like the rotating blades, the rotating aerofoils, and vortex shedding), have a very bad response on the pulsed modulation. Finally, the fluctuating fluid shear stress audible sources, where the net fluid volume nor net force equal zero (like the jet flows, the vibrating spheres and the tuning forks), have a very long pulse width in spite of their good frequencyselectivity. In this work, we have combined the fluctuating fluid volume-mass and the fluctuating fluid shear stress audible sources into a new hybrid category. The idea behind this combination, is to make use of the high power and the short pulse-width LIB, to induce a Helmholtz resonance inside a hollow metallic spheres. The yielded high power impulse frequency spectrum is then customized according to the geometrical shape, the optical and physical parameters, and independent on the LIB 
uncontrolled high frequency bandwidth. Unlike dodecahedron speakers [3], the proposed method merged between the tuned high power audible bursts and the short emission duration in one design, where the sound radiation omnidirectivity is pretty much the same. To maximize the acoustic yield of the resonator, the pulsed laser beam is focused through a fine hole, on the internal wall of the spherical cavity (as shown in figure 1a), resulting in ablating the thin metallic layer and the generating a high pressure plasma plume (as shown in figure 1b).

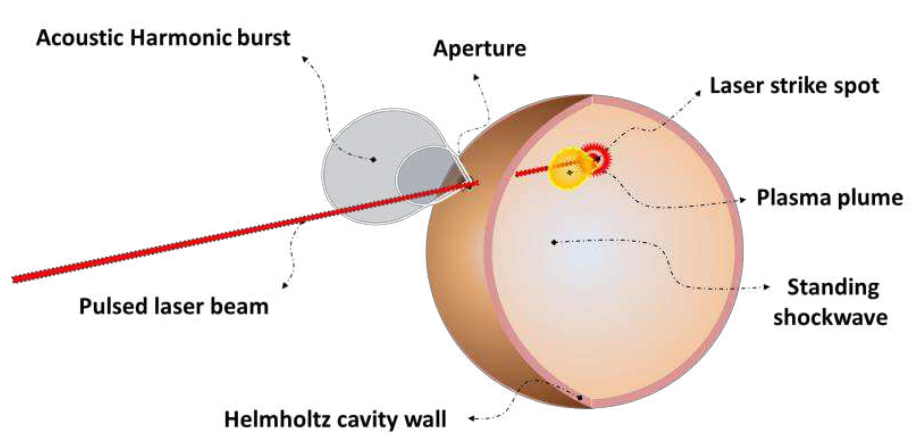

(a)

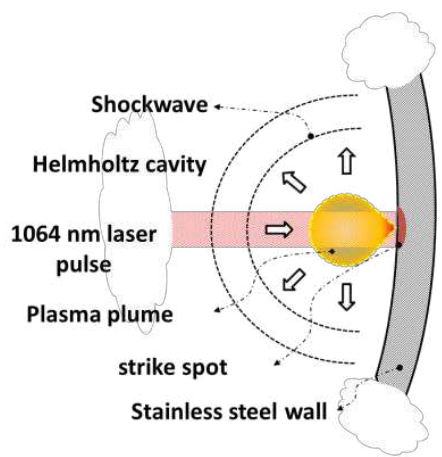

(b)

Figure 1. Illustration of the laser induced plasma Helmholtz resonator: (a) An imaginary section in the resonator showing the laser strike spot and the plasma plume shockwave (b) Plasma Plume formation

Hence, the wall of the resonator was selected to be made from a ferrous alloy, such as stainless steel, to withstand the successive laser ablative interaction [4]. The confined plasma plume induces a series of harmonic standing waves bursts, where the characterization of such acoustic yield is the subject of this work. Since that the used Helmholtz resonator was manufactured in form of a spherical cavity of relatively thin metallic shell, then spherical harmonics reactions are expected to propagate through the walls. The photoacoustic/thermoelastic reactions [5] will be ignored, and our analysis will be focused on the through-air Laser-induced plasma (LIP) acoustics. The prospective applications of this method in physical testing and engineering that requires a spherical sound field are numerous [6]. For example, the architectural acoustics, the impact sound level measurements, the airborne sound insulation, the reverberation time testing, the audio calibration, and the standard acoustic testing (where the most important are the ISO 3382, ISO 140, ISO 10140, ISO 16283, and ISO 717 test series). The key component in these tests, is the dodecahedron loudspeaker (shown in figure 2a) that is capable of delivering a Sound Pressure Level (SPL) up to $120 \mathrm{~dB}$. This type of acoustic transducers is made from a polymeric hollow chassis in the form of a regular dodecahedron with 12 faces, each one has a dynamic speaker. All speakers are connected together in phase, in order to produce an overlapped homogeneous sound field that simulates an acoustic point source [7]. As shown in figure $2 \mathrm{~b}$, the dodecahedron loudspeaker has a spherical sound field at the low frequencies (i.e. $100 \mathrm{~Hz}$ ), but it appears to turn into the flower shape at the high frequencies (i.e. $3.15 \mathrm{KHz}$ ) [8], which is not the case for our method.

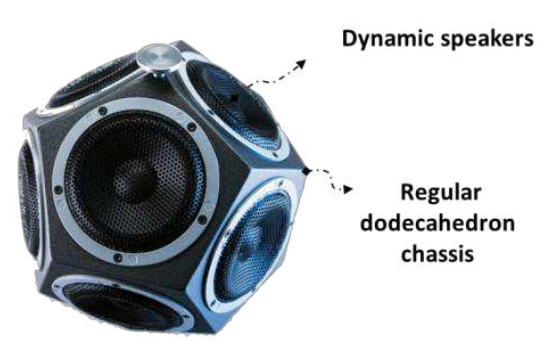

(a)

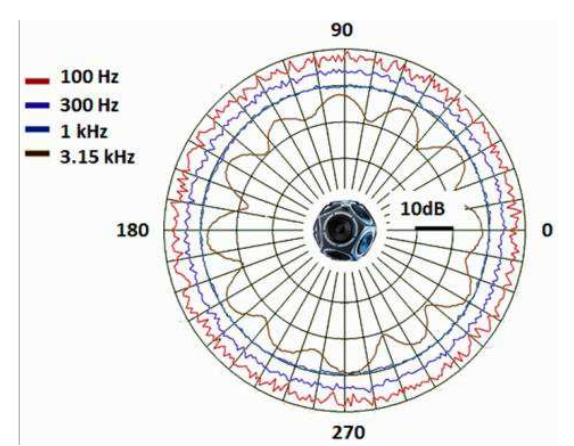

(b) 
Figure 2. Typical dodecahedron loudspeaker (a) assembly (b) sound field polar plot

\section{Theory}

The kernel of this work is to transform the energy of the LIP (with a high-frequency acoustic response [9]) into a long-lasting harmonic acoustic pulse with a custom lower frequency spectrum. To achieve this goal, a simple derivation is used to build up a theoretical model, capable of characterizing the basic parameters of this process. So, we started with an intense laser-pulse striking a metallic surface in the $\mathrm{x}-\mathrm{y}$ plane, then an induced ablative-reaction starts, and a plasma plume is formed. This particular interaction can be modeled through the one-dimensional heat equation, describing the heat flow through the z-direction (which representing the laser-beam propagation), the melting and solidification front, into the irradiated homogenous metal, which take the form [10]:

$$
\rho\left[\mathrm{C}_{\mathrm{p}}+\Delta \mathrm{H}_{\mathrm{m}} \delta\left(\mathrm{T}-\mathrm{T}_{\mathrm{m}}\right)\right]\left(\frac{\partial \mathrm{T}}{\partial \mathrm{t}}-\mathrm{v}_{\mathrm{ab}} \frac{\partial \mathrm{T}}{\partial \mathrm{z}}\right)-\mathrm{K} \frac{\partial^{2} \mathrm{~T}}{\partial \mathrm{z}^{2}}=\alpha(1-\mathrm{R}) \mathrm{I} \mathrm{e}^{-\alpha \mathrm{z}-\int_{\mathrm{t}_{1}}^{\mathrm{t}_{2}} \alpha_{\mathrm{pl}} \mathrm{v}_{\mathrm{pl}} \mathrm{dt}}
$$

Where $\rho$ is metal density, $C_{p}$ is heat capacity of the metal at constant pressure, $T$ is temperature, the melting $\Delta \mathrm{H}_{\mathrm{m}}$ enthalpy at melting point $\mathrm{T}_{\mathrm{m}}, \mathrm{t}$ is the time, $\mathrm{v}_{\mathrm{a}}$ is the ablation velocity, $K$ is the thermal conductivity, $\alpha$ is the absorption coefficient, $\mathrm{R}$ is the reflectivity of the surface, $\alpha_{\mathrm{pl}}$ is the plasma optical absorption coefficient, I is the laser intensity, $v_{p l}$ is the hydrodynamic velocity of the plasma plume. The right hand-side term represents the laser beam as a heating source, over the time interval from $t_{1}$ to $t_{2}$ (representing the time span of the full width at half maximum (FWHM) of the laser pulse). Due to the intense ablative reaction, a thermo-elastic stress waves are generated, with energy proportional to the square of the ablation velocity $v_{a b}$ which is obtained from the Hertz-Knudsen equation using the expression [10]:

$$
\mathrm{v}_{\mathrm{ab}}=0.32\left(\frac{\mathrm{MP}_{\mathrm{s}}}{\rho \mathrm{K}_{\mathrm{B}} \mathrm{T}_{\mathrm{s}}}\right)^{\frac{1}{2}}
$$

Where $T_{S}$ is the metal surface temperature, $P_{S}$ is the saturated vapor pressure above the metal surface, $\mathrm{K}_{\mathrm{B}}$ is the Boltzmann constant and $\mathrm{M}$ is the metal atomic mass. The hydrodynamic velocity of the plasma plume $\mathrm{v}_{\mathrm{pl}}$ is then given by the expression:

$$
\mathrm{v}_{\mathrm{pl}}=0.82\left(\frac{\gamma \mathrm{K}_{\mathrm{B}} \mathrm{T}_{\mathrm{s}}}{\mathrm{M}}\right)^{\frac{1}{2}}
$$

Where $\gamma$ is the ratio between heat capacitances at constant pressure and volume $\left(\frac{C_{p}}{C_{V}}\right)$. The sound intensity $\mathrm{I}_{\mathrm{pl}}$ of the plasma plume shockwave at the Knudsen layer, is approximately the product of $\mathrm{P}_{\mathrm{S}}$ times $v_{\mathrm{pl}}$ hence:

$$
\mathrm{I}_{\mathrm{pl}}=8 \rho \mathrm{v}_{\mathrm{a}}^{2} \gamma^{2}\left(\frac{\mathrm{K}_{\mathrm{B}} \mathrm{T}_{\mathrm{s}}}{\mathrm{M}}\right)^{\frac{3}{2}}
$$

Equation 4 shows that $\mathrm{I}_{\mathrm{pl}}$ is proportional to $\mathrm{T}_{S}^{1.5}$ under the assumption that the plasma formation threshold temperature is exceeded. Hence, $\mathrm{T}_{\mathrm{S}}$ depends on the radiation energy density, the threshold laser fluence $F_{\text {th }}$ of nanosecond plasma formation can be expressed as [11]:

$$
\mathrm{F}_{\mathrm{th}}=\mathrm{L}_{\mathrm{v}}\left(\frac{\tau \rho \mathrm{K}}{\mathrm{C}_{\mathrm{p}}}\right)^{\frac{1}{2}}
$$

Where $L_{v}$ is the latent heat of evaporation and $\tau$ is the laser pulse duration. By solving equation 4 and equation 5 together and by eliminating $\rho$ to obtain the expression:

$$
\mathrm{I}_{\mathrm{pl}}=\frac{8 \mathrm{C}_{\mathrm{p}}}{\tau K} \frac{\mathrm{v}_{\mathrm{ab}}^{2} \gamma^{2} \mathrm{~F}_{\mathrm{th}}^{2}}{\mathrm{~L}_{\mathrm{v}}^{2}}\left(\frac{\mathrm{K}_{\mathrm{B}} \mathrm{T}_{\mathrm{s}}}{\mathrm{M}}\right)^{\frac{3}{2}}
$$


As the plasma plume expands and continue to cool down, the plasma velocity tends to drop quickly, and the shockwave is propagating through the cavity atmosphere at the speed of sound. The sound intensity is proportional to the square of the sound pressure $p$ so that [12]:

$$
\frac{\mathrm{I}}{\mathrm{I}_{\mathrm{o}}}=\frac{\mathrm{p}^{2}}{\mathrm{p}_{\mathrm{o}}^{2}}
$$

By choosing $\mathrm{I}=\mathrm{I}_{\mathrm{pl}}, \mathrm{I}_{\mathrm{o}}=1 \times 10^{-12} \mathrm{~W} / \mathrm{m}^{2}$ which is a standard reference value and by choosing $\mathrm{p}_{\mathrm{o}}=20 \times 10^{-6} \mathrm{~Pa}$ which represents the hearing threshold pressure, then the sound pressure in front of the plasma plume is given by the expression:

$$
\mathrm{p}_{\mathrm{pl}}=14.37 \frac{\gamma \mathrm{vab}_{\mathrm{ab}} \mathrm{F}_{\mathrm{th}}}{\mathrm{L}_{\mathrm{v}}}\left(\frac{\mathrm{C}_{\mathrm{p}}}{\tau \mathrm{K}}\right)^{\frac{1}{4}}\left(\frac{\mathrm{K}_{\mathrm{B}} \mathrm{T}_{\mathrm{s}}}{\mathrm{M}}\right)^{\frac{3}{4}}
$$

Equation 8 shows that the sound pressure at the plasma plume front, does not depend on any geometrical factors related to the target. The SPL expressed in decibels is given by the expression:

$$
\mathrm{SPL}_{\mathrm{pl}(\mathrm{dB})}=20 \log _{10}\left(\frac{\mathrm{p}_{\mathrm{pl}}}{\mathrm{p}_{\mathrm{o}}}\right)=20 \log _{10}\left(\frac{7.1865 \times 10^{5} \gamma \mathrm{vaF}_{\mathrm{th}}}{\mathrm{L}_{\mathrm{v}}}\left(\frac{\mathrm{C}_{\mathrm{p}}}{\tau K}\right)^{\frac{1}{4}}\left(\frac{\mathrm{K}_{\mathrm{B}} \mathrm{T}_{\mathrm{s}}}{\mathrm{M}}\right)^{\frac{3}{4}}\right)
$$

The shockwave induces a wide range of harmonic standing waves inside the Helmholtz cavity, each one has a specific intensity given by the expression:

$$
\mathrm{I}_{\mathrm{H}_{n}}=2 \rho_{\text {air }} \mathrm{C} \pi^{2} \mathrm{n}^{2} \delta_{\mathrm{n}}^{2} \mathrm{f}_{\mathrm{H}}^{2}
$$

Where $\rho_{\text {air }}$ is air density, $\mathrm{C}$ is the sound speed in air, $\mathrm{n}$ is the harmonic multiplicity, $\delta_{n}$ is the amplitude of pressure variation and $\mathrm{f}_{\mathrm{H}}$ is the fundamental Helmholtz frequency, which is given by the expression [13-15, 22-24]:

$$
\mathrm{f}_{\mathrm{H}}=\frac{\mathrm{dC}}{\pi} \sqrt{\frac{3}{8(\mathrm{~L}+0.85 \mathrm{~d}) \mathrm{D}^{3}}}
$$

Where $D$ is the entrance hole diameter, is the internal cavity diameter and $\mathrm{L}$ is the true length of the neck. Since $C=3400 \mathrm{~s}$ and $\mathrm{L}=0$ for neckless Helmholtz cavities, therefore equation 11 can be simplified to:

$$
\mathrm{f}_{\mathrm{H}}=72.6 \sqrt{\frac{\mathrm{d}}{\mathrm{D}^{3}}}
$$

Usually, Helmholtz cavities have a very strong resonance at $f_{H}$, with no higher-order harmonics due to the presence of the neck, controlling the acoustic impedance of the system. But in our case, where the cavity has no neck, it is possible to generate higher order harmonics. Since the energy of the plasma shockwave is transformed into harmonic standing waves of different pressure amplitudes then:

$$
\mathrm{I}_{\mathrm{pl}}=\sum_{\mathrm{n}=1}^{\infty} \mathrm{I}_{\mathrm{H}_{n}}=2 \rho_{\text {air }} \mathrm{C} \pi^{2} \mathrm{f}_{\mathrm{H}}^{2} \sum_{n=1}^{\infty} \mathrm{n}^{2} \delta_{\mathrm{n}}^{2}
$$

Equation 13 is just an acceptable approximation to simplify the analysis. If a detailed analysis is required for decomposing the pressure amplitude, then a standard discrete Fourier transform should be applied and followed by Paseval's inversion theorem. Applying equations 6 and 12 into equation 13 we obtain the expression:

$$
\sum_{n=1}^{\infty} \mathrm{n}^{2} \delta_{\mathrm{n}}^{2}=\frac{0.7589 \times 10^{-3} \mathrm{D}^{3} \mathrm{C}_{\mathrm{p}}}{\mathrm{C} \tau \mathrm{Kd} \rho_{\text {air }}} \frac{\mathrm{v}_{\mathrm{ab}}^{2} \gamma^{2} \mathrm{~F}_{\mathrm{th}}^{2}}{\pi^{2} \mathrm{~L}_{\mathrm{v}}^{2}}\left(\frac{\mathrm{K}_{\mathrm{B}} \mathrm{T}_{\mathrm{s}}}{\mathrm{M}}\right)^{\frac{3}{2}}
$$

Equation 14 shows that total pressure amplitude variation function $\left(\sqrt{\sum_{n=1}^{\infty} \mathrm{n}^{2} \delta_{\mathrm{n}}^{2}}\right)$ at the plasma threshold, is proportional to $\mathrm{D}^{1.5}$ and $\mathrm{d}^{-0.5}$ which are a geometrical parameters, $\mathrm{F}_{\text {th }}$ and $\tau^{-0.5}$ which are a radiation parameters and proportional to $\mathrm{v}_{\mathrm{ab}}, \mathrm{T}_{\mathrm{S}}^{0.75}, \mathrm{M}^{-0.75}, \mathrm{~L}_{\mathrm{v}}^{-1}, \mathrm{c}_{p}^{0.5}, \gamma$ and $\mathrm{K}^{-0.5}$, which are all a material characteristic-parameters. This result will help us in optimizing our selection for the suitable material that produces the maximum sound pressure in this particular application. For example, the best material should be made of a metal of low atomic-mass and high melting-point. Since the other parameters are almost similar for most metals, especially the heat capacitance, it is 
recommended to select an alloy with a good mechanical and chemical properties, which withstands the extreme operation-condition under the high-power laser irradiation. One of the best materials for this application [16] is the stainless steel which has a good oxidization resistance, a high melting point, and a good mechanical properties. One more advantage is that stainless steel alloys contain $\mathrm{Ni}$, $\mathrm{Cr}$, and $\mathrm{Mo}$ in addition to $\mathrm{Fe}$ (the major constituent), which are all transition elements from the same $3 \mathrm{~d}$ group in the periodic table of elements. These elements are close in atomic mass so that $\mathrm{M}$ in our calculation will be based on that of Fe. It should be mention that $F_{\text {th }}$ depends strongly on the laser wavelength $\lambda_{\mathrm{L}}$. Therefore, $\mathrm{I}_{\mathrm{pl}}$ will depend proportionally on the laser fluence $\mathrm{F}$ at this specific wavelength and pulse duration. In general, the plasma plume lasts for more than $20 \mathrm{~ns}$ in case of Qswitched LIP, but the acoustic pressure signal will last very much longer. The acoustic pulse duration depends basically on acoustic time constant of the Helmholtz resonator cavity $\tau_{c}$, where the impulse response of the cavity (defined as the ratio of the output to input sound intensity $\frac{I_{\text {out }}}{I_{\text {in }}}$ ) is given by the expression:

$$
\frac{\mathrm{I}_{\text {out }}}{\mathrm{I}_{\text {in }}}=\left(\frac{\mathrm{p}_{\text {out }}}{\mathrm{p}_{\mathrm{pl}}}\right)^{2}=\mathrm{e}^{-1 / \mathrm{f}_{\mathrm{H}} \tau_{\mathrm{c}}}
$$

Moreover, $\tau_{\mathrm{c}}$ can be calculated from the basic expression:

$$
\tau_{\mathrm{c}}=\frac{\mathrm{Q}}{\pi \mathrm{f}_{\mathrm{H}}}
$$

Where $\mathrm{Q}$ is the quality factor of the resonator. Eventually, the repetition rate of the laser pulses equals that of the acoustic bursts as long as their relaxation time is always smaller then the time between two successive laser pulses. One important issue that should be mentioned before ending our formulation, is the mode coupling. This phenomena controls the amplification of some harmonic mode over others. One of the principle causes of this phenomena, is the surface acoustic waves propagating through the spherical shell of the Helmholtz cavity [5], at sixteen times the sound speed in air and causing complex breathing modes as shown in figure 3 .
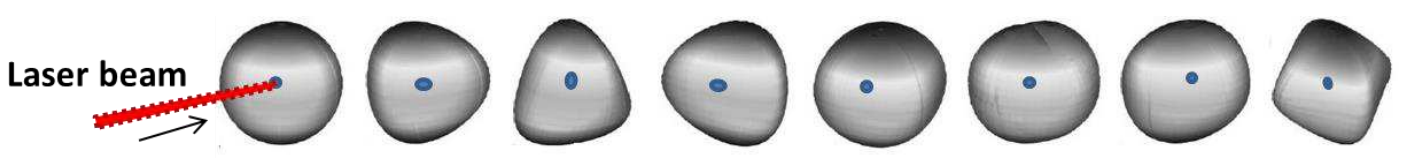

Figure 3. Illustration of cavity breathing modes as a result of an intense laser thermoelastic impulse

These elastic modes participate in the inhalation and the creation of Helmholtz harmonic pressure oscillations in front of the shockwave of plasma plume, by scattered reflection and interference. To minimize the effect of this phenomena on the acoustic harmonic yield of the resonator, it is recommended to avoid using cavities of thin shell thickness, in order to quench Rayleigh-Lambert and Tesseral waves. It is recommended also to control the laser fluence to moderate the generation of thermoelastic reaction inside the cavity wall. If the laser wavelength is changed at constant fluence, it is expected that mode coupling will take place, because of the dependency of wall reflectivity on laser wavelength. Usually, the metallic reflectivity drops at high laser fluence to $20 \%$ of its original value [17], causing more energy absorption, higher thermoelastic reaction, and consequently higher cavity vibration modes.

\section{Experimental Work}

The aim of the experimental work, is to measure and characterize the effect of cavity diameter, laser wavelength and fluence on the temporal acoustic yield of the spherical Helmholtz resonators. Finally, to evaluate the performance of this method in comparison with dodecahedron speaker.

\subsection{Experimental Samples}

According to equation 8, the resonator material is selected from Ashby diagrams to satisfy and maximize the acoustic pressure yield of the method. AISI 316L stainless steel was our selection that 
fulfill the parametric requirements previously discussed in section 2. Table 1 summarizes the most important physical characteristics for the selected material.

Table 1. Physical characteristics of AISI 316L stainless steel*.

\begin{tabular}{ccccccccc}
\hline $\begin{array}{c}\mathbf{C}_{\mathbf{p}} \\
(\mathrm{kJ} / \mathrm{kg} . \mathrm{K})\end{array}$ & $\begin{array}{c}\boldsymbol{\gamma} \\
(-)\end{array}$ & $\begin{array}{c}\Delta \mathbf{H}_{\mathbf{m}} \\
(\mathrm{kJ} / \mathrm{kg})\end{array}$ & $\begin{array}{c}\mathbf{L}_{\mathbf{v}} \\
(\mathrm{kJ} / \mathrm{kg} . \mathrm{K})\end{array}$ & $\begin{array}{c}\mathbf{K} \\
(\mathrm{W} / \mathrm{m} . \mathrm{K})\end{array}$ & $\begin{array}{c}\mathbf{T}_{\text {melting }} \\
(\mathrm{K})\end{array}$ & $\begin{array}{c}\mathbf{F}_{\text {th 1064nm }} \\
\left(\mathrm{J} / \mathrm{cm}^{2}\right)\end{array}$ & $\begin{array}{c}\mathbf{F}_{\text {th 532nm }} \\
\left(\mathrm{J} / \mathrm{cm}^{2}\right)\end{array}$ & $\begin{array}{c}\mathbf{F}_{\text {th 355nm }} \\
\left(\mathrm{J} / \mathrm{cm}^{2}\right)\end{array}$ \\
\hline 0.5 & 1.66 & 270 & 6330 & 16 & 1381 & 1.42 & 1.56 & 1.75 \\
{$[16,18]$} & {$[17]$} & {$[17,18]$} & {$[19]$} & {$[16]$} & {$[16]$} & {$[11]$} & {$[11]$} & $\dagger$ \\
\hline
\end{tabular}

* 69wt $\% \mathrm{Fe}, 18 \mathrm{wt} \% \mathrm{Cr}, 10 \mathrm{wt} \% \mathrm{Ni}, 3 \mathrm{wt} \% \mathrm{Mo}$ [16], † Obtained by exponential regression of reference [11] data.

To determine $f_{H}$ for the samples, equation 12 are used to plot $f_{H}$ as a function of $d_{H}$, for two cavities of diameters 11 and $23 \mathrm{~cm}$ respectively (as shown in figure 4a). Then, $\mathrm{d}$ was selected to be of $3.5 \mathrm{~mm}$ for both cavities, leading to a fundamental resonance of $78 \mathrm{~Hz}$ and $31 \mathrm{~Hz}$. If these frequencies are multiplied by the multiplicity n, then we obtain the harmonic Helmholtz spectrum of both cavities as shown in figure $4 \mathrm{~b}$.

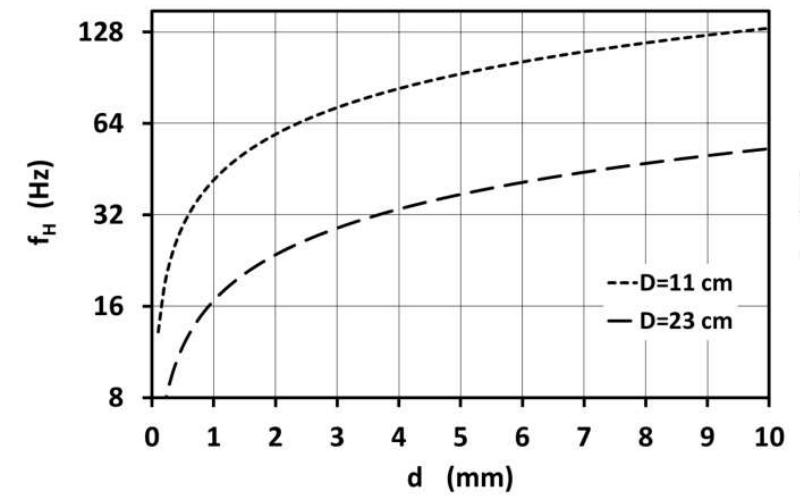

(a)

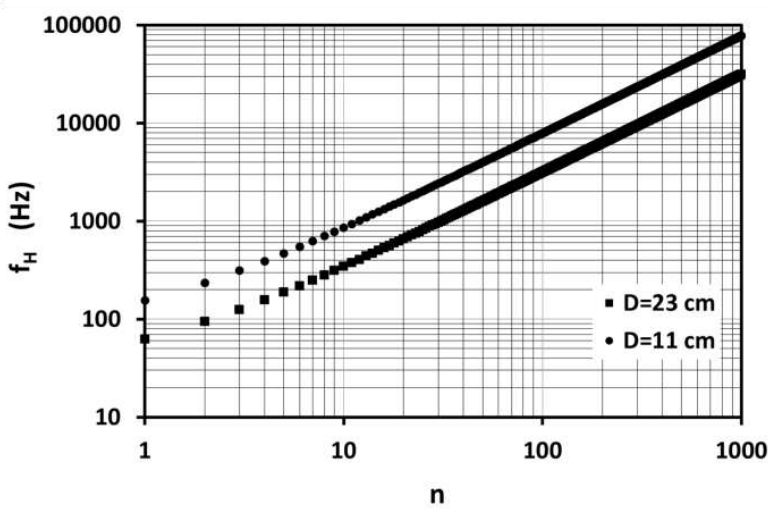

(b)

Figure 4. Effect of sphere diameter on Helmholtz resonance (a) as function of hole diameter (b) as function of multiplicity.

A sheets of $0.5 \mathrm{~mm}$-thick of AISI 316L stainless steel were machined into hemispherical cups using high speed press stamping technique. A special molds where used to produce interlocking edges with a tolerance of $\pm 0.01 \mathrm{~mm}$. The hemispheres were then polished to $1 \mu \mathrm{m}$ roughness and interlocked to form a hollow spheres of 11 and $23 \mathrm{~cm}$ inner diameter. Two holes were drilled in each sphere such that, the first hole was of $3.5 \mathrm{~mm}$ wide, located at the mid distance between a hemisphere's pole and its edge to be used as beam entrance. The second hole was of $4 \mathrm{~mm}$ wide and located $1 \mathrm{~cm}$ from the edge of the other hemisphere, to be used as a mount for an optical fiber window. Both hemispheres were interlocked so that each hole is radially perpendicular to the other.

\subsection{Experimental Setup}
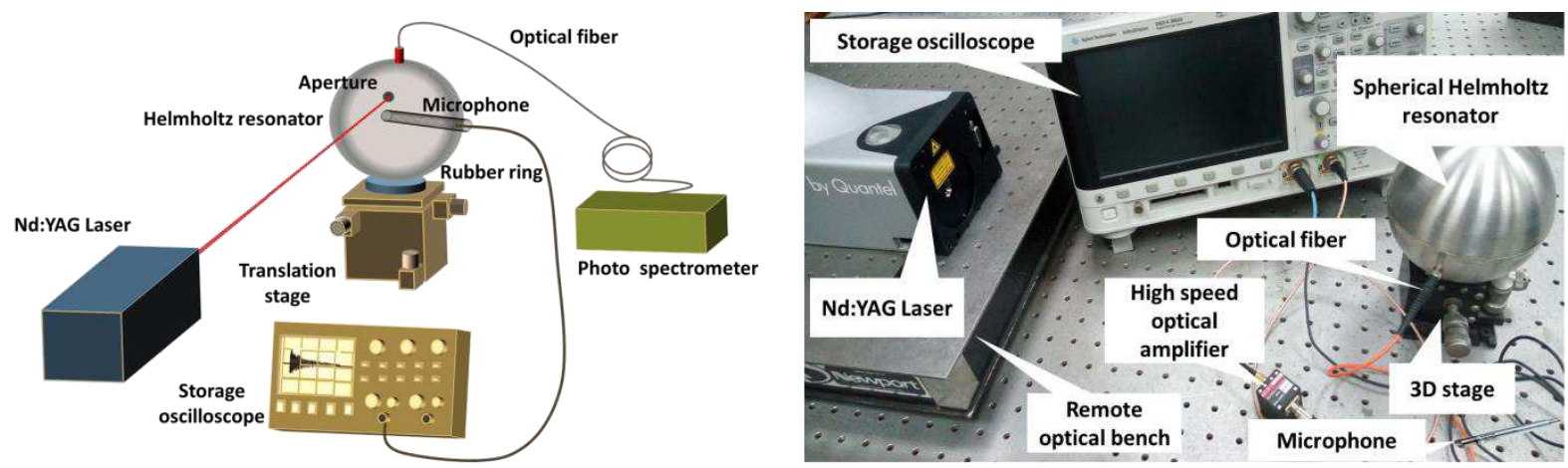
Figure 5. Measurement setup (a) Illustration of the system (b) Experimental setup

An experimental setup was designed to measure the sound pressure and the LIB spectrum of a $\mathrm{Nd}$;YAG laser generated plasma inside the Helmholtz cavities as shown in figure 5a and $5 \mathrm{~b}$. The major components of the setup are: Thorlabs SIR5-FC fast response fiber optic photodetector amplifier was used at first for beam characterization. Ocean optics USB4000 VIS-NIR spectrometer was used for spectral irradiance and LIP spectroscopy. The experimental setup shown in figure $5 \mathrm{~b}$ is consisting of a Quantel Q-smart $450 \mathrm{Nd}$ :YAG laser source (with second and third harmonic generation units) to induce a plasma shocks inside the Helmholtz cavities sphere mounted on $\mathrm{x}-\mathrm{y}-\mathrm{Z}$ precision translation stage. Foam rubber ring of $10 \mathrm{~mm}$-thick and $40 \mathrm{~mm}$ inner-diameter was used to mount the Helmholtz cavities. Pigtailed fiber and sockets for connecting optical devices to the spherical cavities. GRAS 46 high precision flat response microphone connected to a $40 \mathrm{~dB}$ amplifier unit, used for sound pressure measurements. Acoustic insulation foam panels, used to build a $1.75 \times$ $2 \times 2 \mathrm{~m} 2 \mathrm{~m}$ full anechoic chamber around the resonators holder, of $21 \mathrm{~dB}$ noise level. The laser source was placed outside the chamber and the laser beam penetrates inside through a tinny quartz window in the foam panel. The laser divergence was controlled using x10, zoom beam expander/reducer, coated for Nd:YAG laser wavelengths. PixeLink PL-B781U CMOS camera synchronized with the laser source, to acquire the LIP plume peak optical emission profile. Gentec Solo 2, laser energy and power meter, used for laser energy measurements. Finally, TSI Quest SoundPro sound level meter was used to perform average SPL calibrations and measurements. We used an Agilent DSO-X 3052A digital storage oscilloscope/spectrum analyzer to acquire the time and frequency domain data.

Table 2. Physical characteristics of the used laser

\begin{tabular}{cccc}
\hline Wavelength & $1064 \mathrm{~nm}$ & $532 \mathrm{~nm}$ & $355 \mathrm{~nm}$ \\
\hline Energy per pulse & $450 \mathrm{~mJ}$ & $220 \mathrm{~mJ}$ & $130 \mathrm{~mJ}$ \\
Pulse duration & $6 \mathrm{~ns}$ & $5 \mathrm{~ns}$ & $5 \mathrm{~ns}$ \\
\hline
\end{tabular}

\subsection{Experimental Procedure}

The experimental procedure was performed on 4 stages, each stage was repeated 3 times using different laser wavelengths. In some particular stages, the tests were repeated twice using different sphere diameter. The first stage was to characterize the laser pulses inside the resonator by connecting the fast response fiber optic photodetector amplifier to the Helmholtz cavity. In this stage, the SLP was measured using the microphone placed just near the entrance hole, to characterize the acoustic output signal. The second stage was to acquire the SPL inside the anechoic chamber and to plot the acoustic pressure field around the resonator with the microphone. In this stage the laser was kept outside the chamber, to exclude the laser head discharge noise from being measured. The third stage was to characterize the LIP spectral irradiance inside the cavity, by connecting the fiber optic spectrometer to the resonator. Finally, the fourth stage was to capture the peak optical emission profile of LIP plume on the outer surface of the cavity, since it was difficult to introduce the camera inside the closed sphere. Part of the data analysis was performed using Mikropack-SpecLine and DADiSP softwares.

\section{Results and analysis}

All of the acquired data during the experimental procedure was processed, plotted and summarized in the following order:

\subsection{Effect of resonator diameter on the acoustic output}

\section{(i) Impulse response}




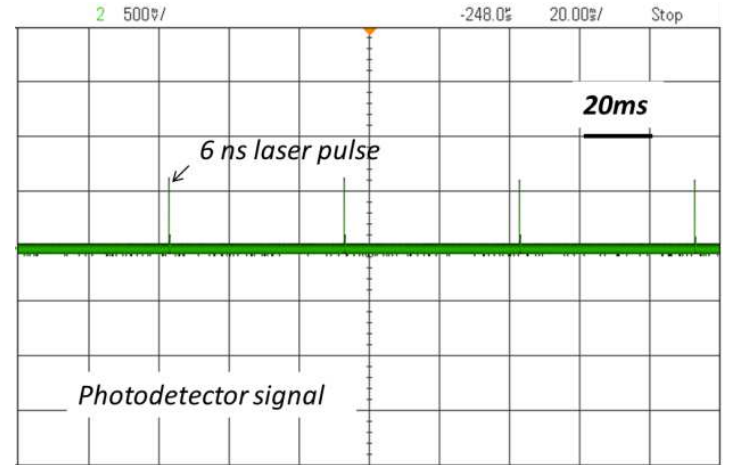

(a)

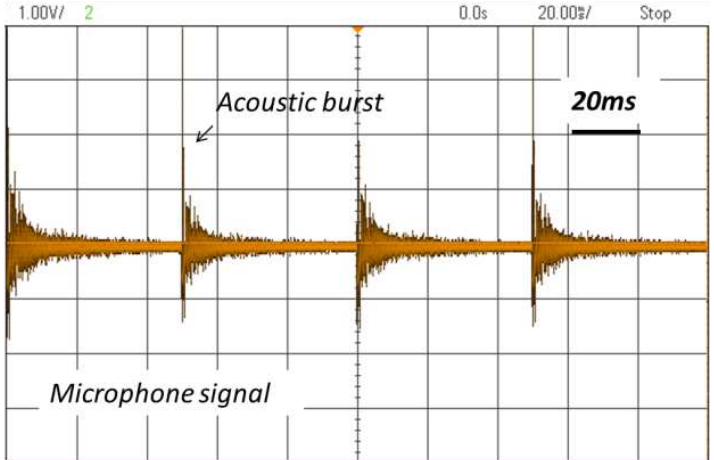

(b)

Figure 6. $20 \mathrm{~Hz}$ pulse train of (a) $1064 \mathrm{~nm}, 6 \mathrm{~ns} \mathrm{Nd}$ :YAG laser irradiating the inner surface of a $23 \mathrm{~cm}$ diameter Helmholtz cavity at $5 \mathrm{~J} / \mathrm{cm}^{2}$ fluence (b) acoustic burst of standing Helmholtz pressure wave at the cavity entrance hole.

As shown in figure $6 \mathrm{a}$, a train of pulses (with wavelength $=1064 \mathrm{~nm}$, and pulse width $=6 \mathrm{~ns}$ ) struck the inner surface of the $23 \mathrm{~cm}$-diameter cavity, at $20 \mathrm{~Hz}$ repetition rate. In response, an analogue train of acoustic bursts, was received by the microphone $3 \mathrm{~cm}$-apart from the cavity entrance hole. The bursts were stable, repetitive and identical in shape as shown in figure $6 \mathrm{~b}$. Noting that the laser fluence was about $5 \mathrm{~J} / \mathrm{cm}^{2}$, which is larger than $\mathrm{F}_{\text {th }}$, in order to guarantee the formation of LIP plume. The time constant of the decayed oscillations was in the order of 21 to $25 \mathrm{~ms}$. A similar but different results were obtained with other laser wavelengths. When the diameter of the resonator was reduced to $11 \mathrm{~cm}$, the time constant dropped to a less than 4 to $5 \mathrm{~ms}$ depending on the used laser wavelength. The delay time between optical impulse and the acoustic signal is less than $0.79 \mathrm{~ms}$ in most cases.

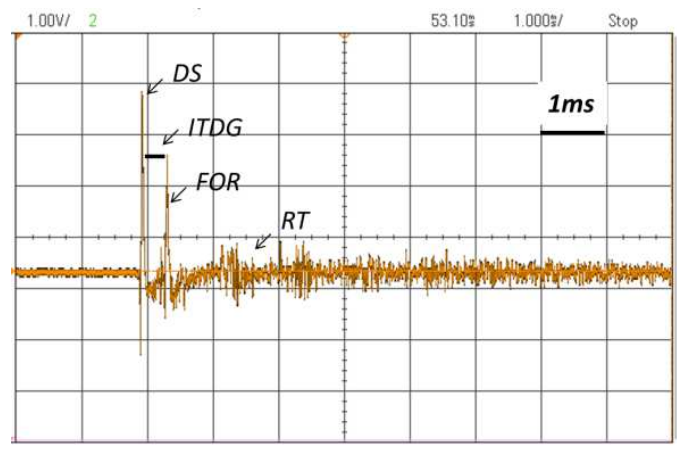

(a)

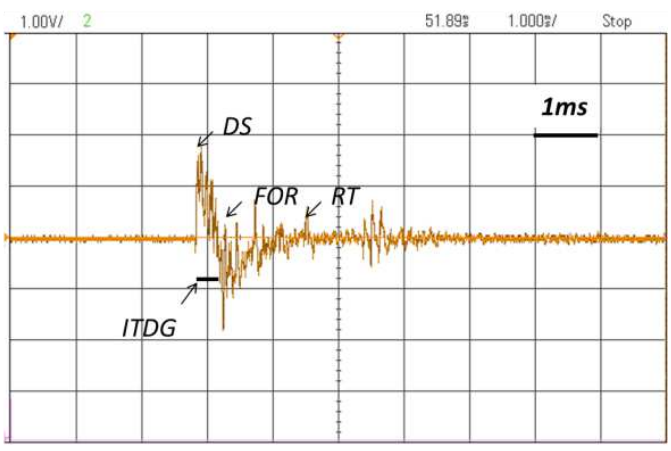

(b)

Figure 7. Impulse response of the Helmholtz cavities for (a) $D=23 \mathrm{~cm}$ (b) $D=11 \mathrm{~cm}$.

As shown in figure 7a, the impulse response of the larger cavity is characterized by a high pressure direct sound (DS) peak of pulse duration $\tau_{\mathrm{DS}}$, followed by an initial time delay gap (ITDG) of 0.25 ms separating a first order reflection (FOR) and reverberant tail (RT). To calculate the distance from the microphone to the cavity surface, we can multiply half the ITDG times the speed of sound to yield a reasonable span of approximately $4.25 \mathrm{~cm}$. In this context, the RT could be of non-architecture origin, since that the measurement took place in anechoic chamber. The time interval separating the RT signal is almost $1 \mathrm{~ms}$, representing a cavity flexure modes of $1 \mathrm{kHz}$. The complexity of the flexure peaks is due to modulation by cavity breathing modes. As shown in figure $7 \mathrm{~b}$, when the diameter of the cavity is reduced to $11 \mathrm{~cm}$, the DS pressure peak and the FOR amplitude also decreased. The ITDG remains unchanged, but the RT has become of much shorter interval representing a cavity flexure modes of $2.5 \mathrm{kHz}$, causing the broadening DS profile. 


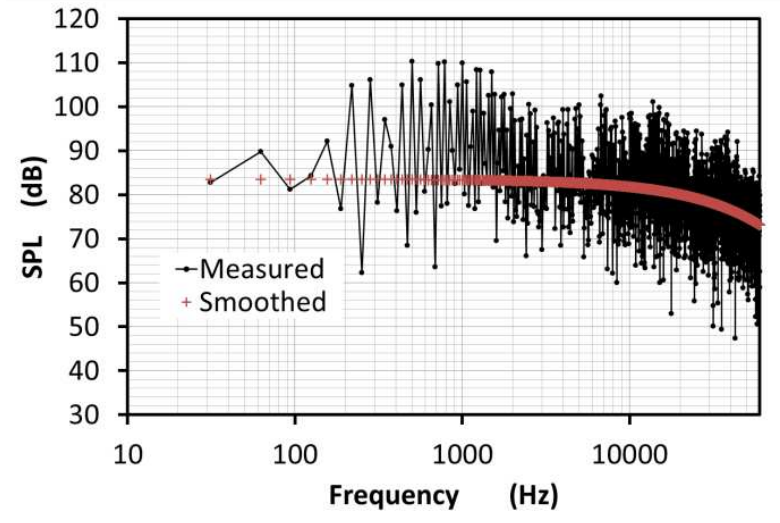

(a)

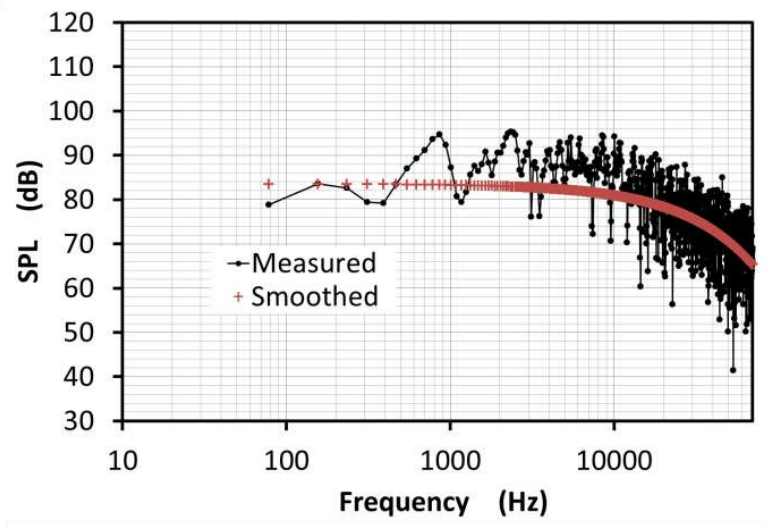

(b)

Figure 8. Frequency response of Helmholtz cavities of (a) $D=23 \mathrm{~cm}$ (b) $D=11 \mathrm{~cm}$

As shown in figures $8 \mathrm{a}$ and $8 \mathrm{~b}$, the acoustic spectral response for both cavities was obtained by applying fast Fourier transforms (FFT) on the impulse responses of figures $7 \mathrm{a}$ and $7 \mathrm{~b}$. Both spectral patterns showed an exponential SPL decay as proceeding toward the high-end band that can be smoothed and approximated using the empirical expression:

$$
\mathrm{SPL}_{\text {approximated }(\mathrm{dB})}=\mathrm{ae}^{\mathrm{nbf}_{\mathrm{H}}}=\left(20 \log _{10} \frac{\overline{\mathrm{V}}_{\mathrm{m}} \mathrm{G}}{\mathrm{p}_{\mathrm{o}} \mathrm{S}}\right) \mathrm{e}^{72.6 \mathrm{nb} \sqrt{\frac{\mathrm{d}_{\mathrm{h}}}{\mathrm{D}^{3}}}}
$$

Where a is the average SPL, represented as a function of the voltage signal $\bar{V}_{\mathrm{m}}$, obtained by a microphone of pressure sensitivity S, followed by an amplifier of gain $G$, and $b$ is the attenuation coefficient. The value of a is very broad and ranging from 53 to $83 \mathrm{~dB}$, unlike the value of $\mathrm{b}$, which equals approximately from -3 to $-4 \times 10^{-6} \mathrm{~Hz}^{-1}$, over the whole wavelength range of the used laser. The peak pressure variation $\delta_{\max }$ occurred at $\mathrm{n}=16$ for the large cavity and at $\mathrm{n}=29$ for the small cavity at laser wavelength of $1064 \mathrm{~nm}$. Then, $\delta_{\max }$ occurred at $\mathrm{n}=26$ for the large cavity and $\mathrm{n}=104$ for the small cavity at laser wavelength of $532 \mathrm{~nm}$. And finally drops to $n=23$ for the large cavity and $n=33$ for the small cavity at laser wavelength of $355 \mathrm{~nm}$. The peak pressure resonance frequency for the large cavity is one order of magnitude less than that of the small cavity. The reason behind the generation of higher frequency modes in case of the $532 \mathrm{~nm}$ laser, may due to low plasma selfabsorption, which led to higher thermoelastic cavity modes. A summary of resonators temporal and spectral responses versus laser wavelength is inclusive in table 3.

Table 3. Summary of resonators temporal and spectral responses versus laser wavelength

\begin{tabular}{|c|c|c|c|c|c|c|}
\hline & & $\mathbf{D}=11 \mathrm{~cm}$ & & & $\mathbf{D}=23 \mathrm{~cm}$ & \\
\hline & $\lambda=1064 \mathrm{~nm}$ & $\lambda=532 \mathrm{~nm}$ & $\lambda=355 \mathrm{~nm}$ & $\lambda=1064 \mathrm{~nm}$ & $\lambda=532 \mathrm{~nm}$ & $\lambda=355 \mathrm{~nm}$ \\
\hline$\tau_{c}$ & $0.005 \mathrm{~s}$ & $0.0047 \mathrm{~s}$ & $0.0046 \mathrm{~s}$ & $0.025 \mathrm{~s}$ & $0.023 \mathrm{~s}$ & $0.021 \mathrm{~s}$ \\
\hline$\tau_{\mathrm{DS}}$ & $0.0045 \mathrm{~s}$ & $0.0044 \mathrm{~s}$ & $0.0044 \mathrm{~s}$ & $0.00012 \mathrm{~s}$ & $0.00011 \mathrm{~s}$ & $0.00011 \mathrm{~s}$ \\
\hline $\mathbf{f}_{\mathrm{H}}$ & $78 \mathrm{~Hz}$ & $78 \mathrm{~Hz}$ & $78 \mathrm{~Hz}$ & $31.25 \mathrm{~Hz}$ & $31.25 \mathrm{~Hz}$ & $31.25 \mathrm{~Hz}$ \\
\hline $\mathbf{f}_{\left(\boldsymbol{\delta}_{\max }\right)}$ & $2262 \mathrm{~Hz}$ & $8112 \mathrm{~Hz}$ & $2574 \mathrm{~Hz}$ & $500 \mathrm{~Hz}$ & $812.5 \mathrm{~Hz}$ & $718.75 \mathrm{~Hz}$ \\
\hline $\mathbf{Q}_{\mathrm{f}_{\mathrm{H}}}$ & 1.225 & 1.151 & 1.127 & 2.45 & 2.25 & 2.06 \\
\hline $\mathbf{Q}_{\mathbf{f}_{\left(\delta_{\max }\right)}}$ & 35.53 & 119.77 & 36.38 & 39.26 & 58.74 & 47.41 \\
\hline a & $81.496 \mathrm{~dB}$ & $63.792 \mathrm{~dB}$ & $33.921 \mathrm{~dB}$ & $83.401 \mathrm{~dB}$ & $78.66 \mathrm{~dB}$ & $53.879 \mathrm{~dB}$ \\
\hline$b$ & $-3 \times 10^{-6} \mathrm{~Hz}^{-1}$ & $-4 \times 10^{-6} \mathrm{~Hz}^{-1}$ & $-4 \times 10^{-6} \mathrm{~Hz}^{-1}$ & $-3 \times 10^{-6} \mathrm{~Hz}^{-1}$ & $-4 \times 10^{-6} \mathrm{~Hz}^{-1}$ & $-4 \times 10^{-6} \mathrm{~Hz}^{-1}$ \\
\hline
\end{tabular}


(iii) SPL Field

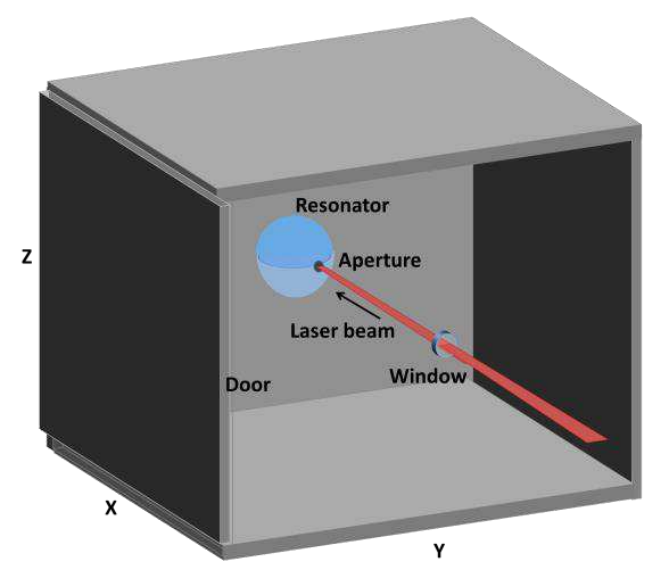

(a)
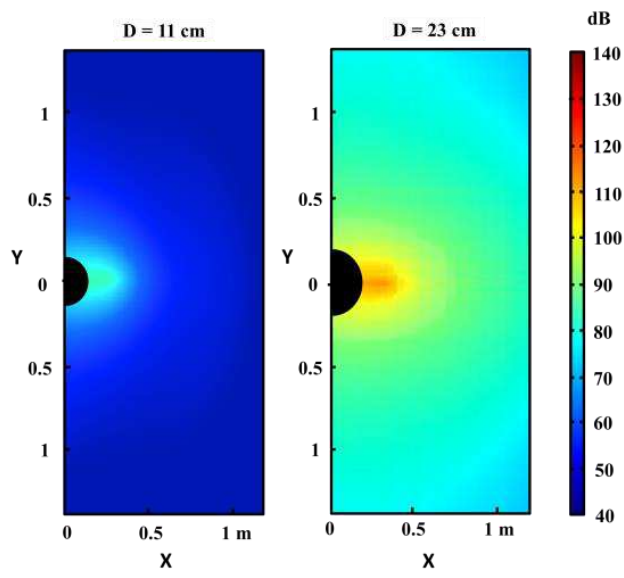

(b)

Figure 9. SPL field measurements (a) illustrative section in the anechoic chamber (b) the average SPL contour plot for both resonators using principal $\mathrm{Nd}$ : YAG laser wavelength at $\mathrm{F}=2 \mathrm{~J} / \mathrm{cm}^{2}$.

As shown in figure 9a, the laser beam lost $4 \%$ of its initial intensity by reflection on the window's surface, but the SPL generated by the photo-acoustic effect was negligible because of the low optical absorption coefficient of quartz. The sound pressure field around the Helmholtz cavities was homogenous, with peak average SPL in front of the resonator holes as shown in figure $9 \mathrm{~b}$. The acoustic yield of the large resonator seemed to be higher than the small one. The contour plot shows a quasi-spherical sound field around the cavities, which means that part of the acoustic pressure is delivered through the solid cavity wall bounce. This result supports our interpretation of mode coupling and its effect in selecting higher-order resonance frequencies. The resultant average SPL field is compared to that of a semi-dodecahedron speaker. It was found also that changing the laser wavelength has no influence on the average SPL field distribution, but has a remarkable effect on the SPL magnitude.

\subsection{Effect of laser wavelength}

\section{(i) Plasma plume shape}

At fixed laser fluence, the plasma vapor temperature $T_{p}$ is the most effective parameter on which depends the pressure of the shockwave in front of the plasma plume. For plasma vapor of sonic speed $\mathrm{T}_{\mathrm{p}} \sim 0.67 \mathrm{~T}_{\mathrm{s}}$ which means that irradiance of the plasma depends upon the temperature of the Knudsen layer [20]. The radius of the plasma plume depends on $\mathrm{T}_{\mathrm{S}}$, but since Mie scattering plays an important role in increasing the amount of absorbed radiation, it is expected that $\mathrm{T}_{\mathrm{p}}$ will be higher than the predicted as the wavelength decreases.

As shown in figure 10a, the plasma plume (induced by the principal Nd:YAG wavelength) has a flame-dome shape of $7 \mathrm{~mm}$ radius, with no apparent optical scattering seen in the direction of the imaging. A similar result was obtained with the second harmonic generation wavelength, but the plasma plume was of $6 \mathrm{~mm}$ radius regular dome shape, with apparent optical scattering seen at the direction of imaging as shown in figure 10b. Finally, a $4 \mathrm{~mm}$ radius dome shape plasma plume with intense apparent optical scattering was induced by the third harmonic generation laser wavelength as shown in figure 10c. 


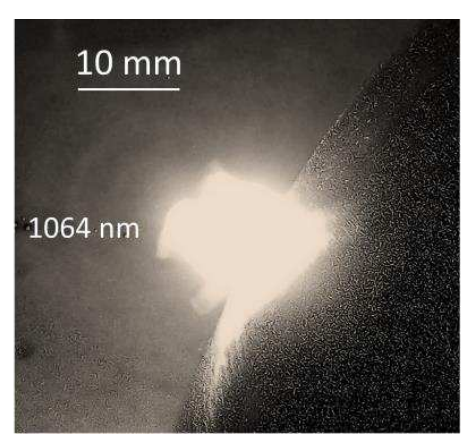

(a)

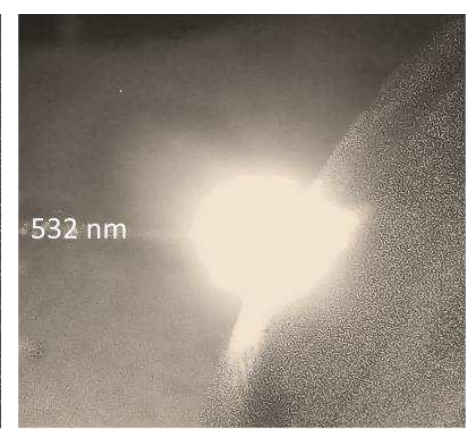

(b)

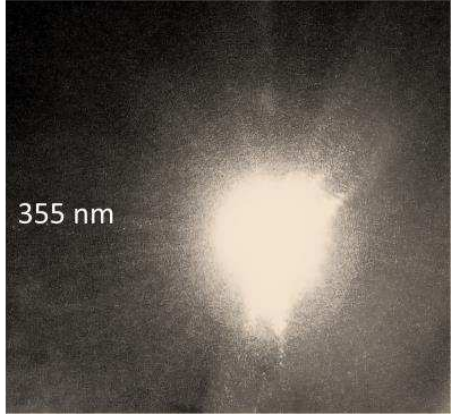

(c)

Figure 10. LIP visible emission from spherical stainless steel surface at atmospheric pressure with synchronized delay of $0.3 \mathrm{~ms}$, frame rate of $75 \mathrm{fps}$, laser fluence of $5 \mathrm{~J} / \mathrm{cm}^{2}$ and wavelength of (a) $1064 \mathrm{~nm}$

(b) $532 \mathrm{~nm}$ (c) $355 \mathrm{~nm}$.

\section{(ii) LIBS analysis}

The spectral irradiance of the obtained plasmas (shown in figure 11), revealed that the thermal yield of the laser interaction with the stainless steel was based on the rotational transition of the ionized atomic constituents rather than the vibrational transitions of the air molecules. The major contributing element was the ionized iron, then came the chromium and the nickel. It was obvious that the principal Nd:YAG laser line, produces the most intense plasma irradiance over the entire VIS/NIR spectrum. It has the strongest effect on ionizing the air atoms in the range from 550 to $650 \mathrm{~nm}$. This could explain why the shape and the length of the plasma plume, induced by this laser wavelength, was the largest among other harmonics (figure 10a). Also, it was noticed that the second harmonic generation laser line has a stronger effect on exciting atmospheric atoms than the third harmonic generation line that eventually has a stronger ionization effect in the spectral range from 355 to 500 $\mathrm{nm}$. This result came into agreement with the visual characterization of figures $10 \mathrm{~b}$ and $10 \mathrm{c}$, where the length of the plasma plume induced by the second harmonic generation laser line, as compared to that generated by the principal line of figure 10a and larger than that of the third harmonic generation line. The reason behind this result may be referred to plasma self-absorption and Mie scattering [20] of the laser radiation by the plasma constituents.

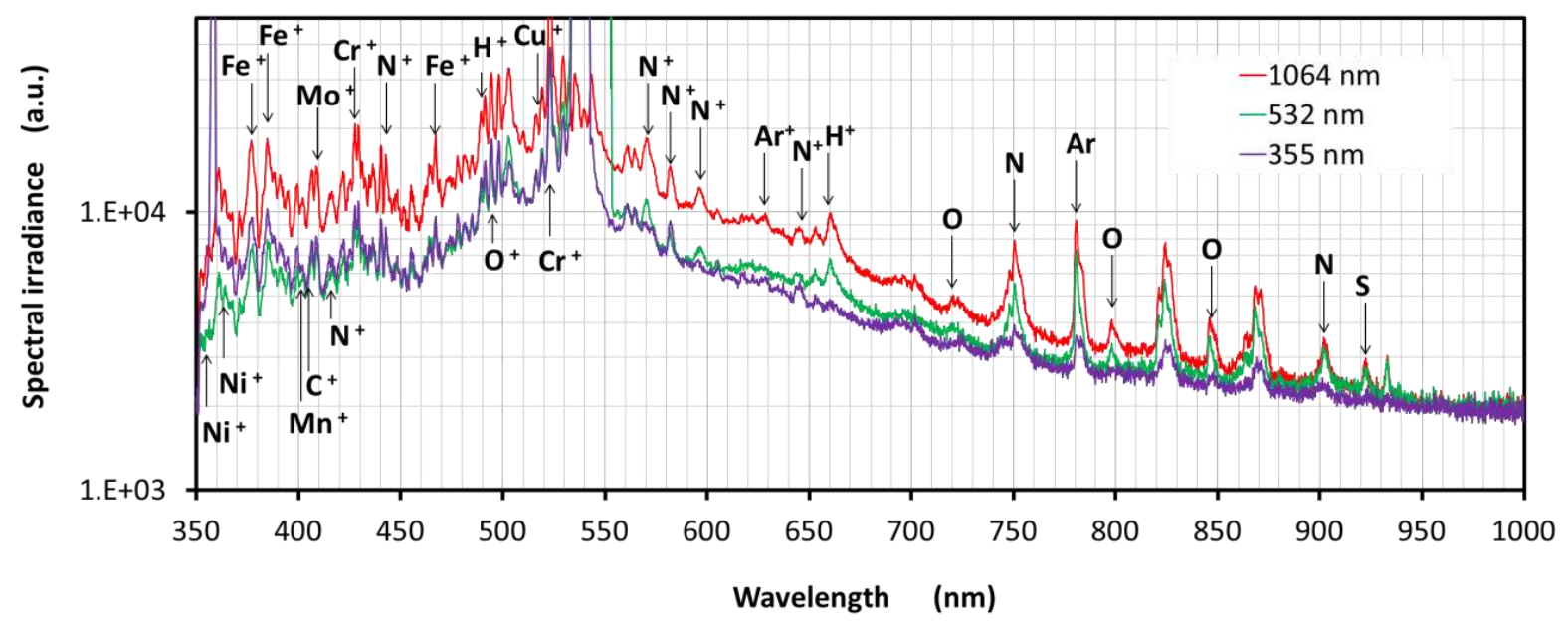

Figure 11. Broad band VIS/NIR plasma spectral irradiance of AISI 316L stainless steel, at distance of 0.05 $\mathrm{mm}$, induced by principal, second and third harmonic generation wavelengths of Q-switched Nd:YAG laser, at $\mathrm{F}=5 \mathrm{~J} / \mathrm{cm}^{2}$. 
To determine the plasma temperature $\mathrm{T}_{p}$ which represents the speed of heavy ions, we must first estimate the electrons temperature $\mathrm{T}_{e}$ by using the Boltzmann plot method [21, 22], given that the intensity of a spectral line representing the transition between two energy levels is given by the expression:

$$
\mathrm{I}_{\mathrm{S}}=\frac{\mathrm{hcg}_{k} \mathrm{~A}_{i k} \mathrm{~N}_{\mathrm{o}}}{4 \pi \mathrm{U} \lambda_{s}} \mathrm{e}^{-\mathrm{E}_{k} / \mathrm{K}_{\mathrm{B}} \mathrm{T}_{\mathrm{e}}}
$$

Where $\mathrm{h}$ is Planck's constant, $\mathrm{c}$ is the velocity of light, $\lambda_{s}$ is the wavelength of optical transition between lower energy states i and higher energy state $\mathrm{k}, \mathrm{g}$ is the degeneracy of upper state, $\mathrm{A}_{i k}$ is the transition probability, $E_{k}$ is the energy of the upper state, $\mathrm{U}$ is the partition function and $\mathrm{N}_{\mathrm{o}}$ is electron density of the state. By modifying equation 18 to yield the expression:

$$
\ln \left(\frac{\lambda_{s} \mathrm{I}_{\mathrm{s}}}{\mathrm{g}_{k} \mathrm{~A}_{i k}}\right)=-\frac{\mathrm{E}_{k}}{\mathrm{~K}_{\mathrm{B}} \mathrm{T}_{\mathrm{e}}}+\ln \left(\frac{4 \pi \mathrm{U}}{\mathrm{hc} \mathrm{N}}\right)
$$

By selecting four $\mathrm{Fe}^{+}$emission lines and plotting $\ln \left(\frac{\lambda_{s} \mathrm{I}_{\mathrm{s}}}{\mathrm{g}_{k} \mathrm{~A}_{i k}}\right)$ versus $\mathrm{E}_{k}$ to obtain the slope $-\frac{1}{\mathrm{~K}_{\mathrm{B}} \mathrm{T}_{\mathrm{e}}}$ and calculate the plasma temperature, assuming that the term $\ln \left(\frac{4 \pi \mathrm{U}}{\mathrm{h} \mathrm{c} \mathrm{N}_{\mathrm{o}}}\right)$ is constant. This procedure was repeated for each of the three laser wavelengths for emission lines $363.14 \mathrm{~nm}, 370.55 \mathrm{~nm}, 387.85$ and, $526.95 \mathrm{~nm}$, corresponding to upper energies of $3,42 \mathrm{eV}, 3.34 \mathrm{eV}, 3.2 \mathrm{eV}$ and $2.36 \mathrm{eV}$. The transition probabilities and the state degeneracies were obtained from standard LIBS data base of reference [23]. The difference between $\mathrm{T}_{e}$ and $\mathrm{T}_{p}$ is only a few thousand of Kelvins so that $\mathrm{T}_{e} \sim \mathrm{T}_{p} \sim 0.67 \mathrm{~T}_{\mathrm{s}}$ approximately. Table 4 summarizes the temperature results obtained from the Boltzmann plots.

Table 4. Calculated plasma temperature for different laser wavelengths

\begin{tabular}{cccc} 
& $1064 \mathrm{~nm}$ & $532 \mathrm{~nm}$ & $355 \mathrm{~nm}$ \\
\hline $\mathbf{T}_{\mathbf{e}}$ & $81000 \mathrm{~K}$ & $74000 \mathrm{~K}$ & $71000 \mathrm{~K}$ \\
$\mathbf{T}_{\mathbf{s}}$ & $54270 \mathrm{~K}$ & $49580 \mathrm{~K}$ & $47570 \mathrm{~K}$ \\
$\mathbf{S P L}_{\mathbf{p l}}$ & $289 \mathrm{~dB}$ & $283 \mathrm{~dB}$ & $279 \mathrm{~dB}$ \\
\hline
\end{tabular}

These results revealed that, under constant fluence, $\mathrm{F}_{\text {th }}$ and $\mathrm{T}_{\mathrm{S}}$ were the most effective parameters in determining the magnitude of sound pressure variation in equation 14, ignoring the optical characteristics of the cavity surface and of the plasma itself. The sources error in our calculations were the exclusion of Mie absorption and the assumption that the plasma gas is monochromatic.

\section{(iii) Acoustic multiplicity versus laser wavelength}

As shown in figure 12, the smaller cavity frequency response for $1064 \mathrm{~nm}$ laser pulse, was of the highest magnitude among other wavelengths, followed by the response for $532 \mathrm{~nm}$, in accordance with the previously obtained temperature results. It was noticed also that the frequency response of the cavity is very poor in the bass range, but very intense in the midrange for all laser wavelengths. At the high-end range, a fast $-3 \mathrm{~dB}$ cutoff of $9.906 \mathrm{kHz}$ was seen in the case of $355 \mathrm{~nm}$ laser pulse and at $18.72 \mathrm{kHz}$ for the $1064 \mathrm{~nm}$ laser pulse. Only the frequency response of the cavity for the $532 \mathrm{~nm}$ laser pulse remained flat at the high-end region. A similar behavior was seen in the case of the larger cavity, but the highest responses occurred at lower frequencies within the same octave ranges. It is good to mention that the $1064 \mathrm{~nm}$ laser pulse tends to induce resonance frequencies of odd multiplicity rather than the other wavelengths that tend to induce resonance frequencies of even multiplicity. This result is illustrated in table 4. The reason behind this behavior, was due to the intensive mode coupling phenomena between the Helmholtz cavity's breathing modes and the acoustic pressure resonance inside it, as mentioned before in section 2 . 


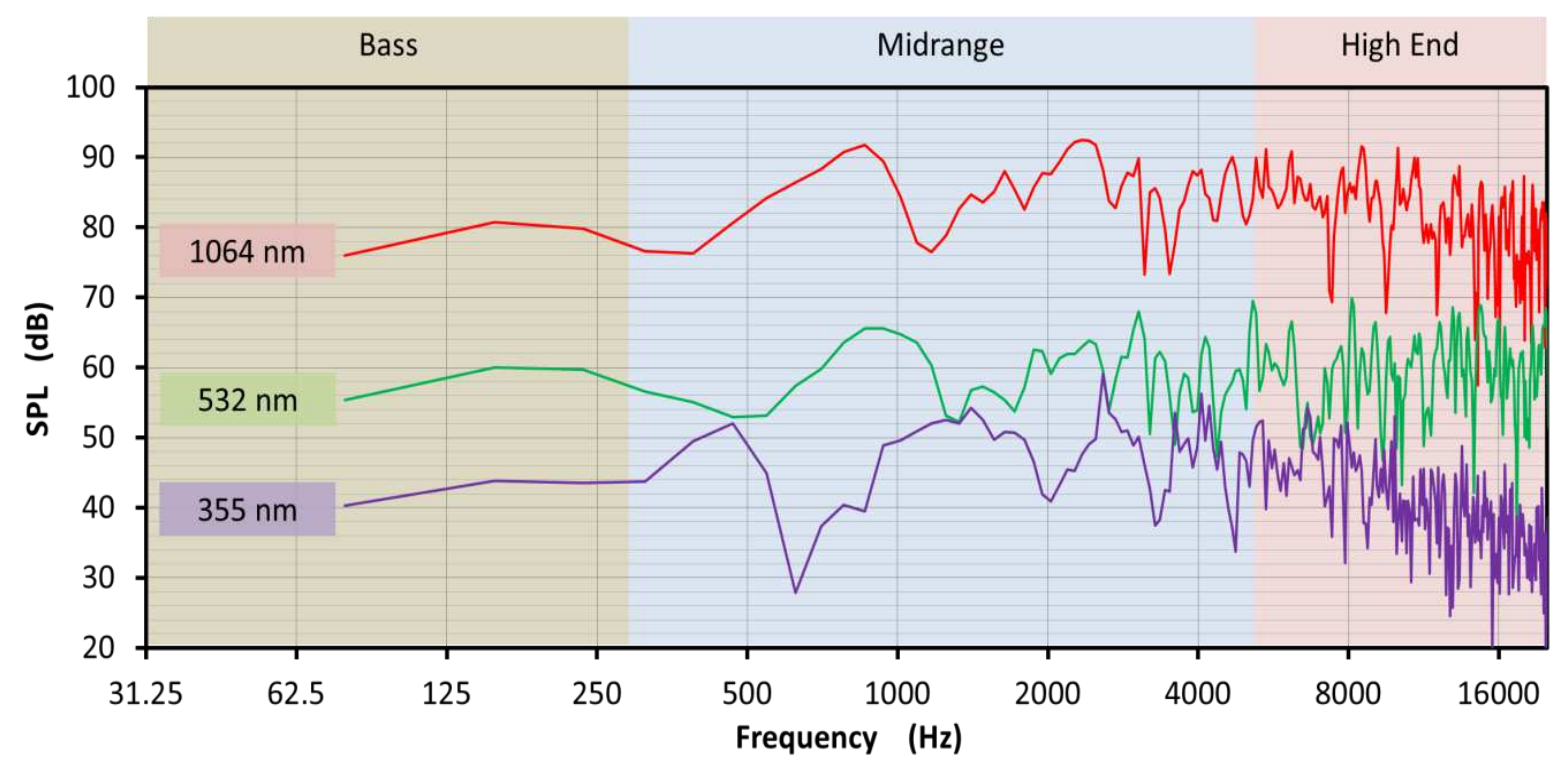

Figure 12. Octave band response of Helmholtz cavity $\mathrm{D}=11 \mathrm{~cm}$ induced by principal, second and third harmonic wavelengths of Q-switched Nd:YAG at $\mathrm{F}=5 \mathrm{~J} / \mathrm{cm}^{2}$.

Table 4. Cavity resonance frequencies of peak response within $-3 \mathrm{~dB}$ amplitude and multiplicity for different laser wave lengths

\begin{tabular}{|c|c|c|c|c|c|}
\hline $\begin{array}{c}\mathbf{f}_{\left(\delta_{\max }\right) \mathbf{1 0 6 4} \mathbf{n m}}(\mathrm{Hz}) \\
\end{array}$ & $\mathrm{n}$ & $\begin{array}{c}\mathbf{f}_{\left(\boldsymbol{\delta}_{\max }\right) 532 \mathbf{n m}} \\
(\mathrm{Hz})\end{array}$ & $\mathrm{n}$ & $\begin{array}{c}\mathbf{f}_{\left(\boldsymbol{\delta}_{\max }\right) 355} \mathbf{n m} \\
(\mathrm{Hz})\end{array}$ & $\mathrm{n}$ \\
\hline $858 \mathrm{~Hz}$ & 11 & 2808 & 36 & 1170 & 15 \\
\hline 1638 & 21 & 3042 & 39 & 1248 & 16 \\
\hline 1950 & 25 & 3276 & 42 & 1404 & 18 \\
\hline 2106 & 27 & 4134 & 53 & $2574 *$ & 33 \\
\hline $2262 *$ & 29 & 5148 & 66 & 2652 & 34 \\
\hline 2886 & 37 & $8112 *$ & 104 & 3588 & 46 \\
\hline 3042 & 39 & 12948 & 166 & 4056 & 52 \\
\hline 4602 & 59 & 14586 & 187 & 4212 & 56 \\
\hline 4758 & 61 & 19812 & 254 & 5226 & 78 \\
\hline 5226 & 67 & - & - & 9906 & 127 \\
\hline 5460 & 70 & - & - & - & - \\
\hline 6084 & 78 & - & - & - & - \\
\hline 6162 & 79 & - & - & - & - \\
\hline 8502 & 109 & - & - & - & - \\
\hline 10062 & 129 & - & - & - & - \\
\hline 10764 & 138 & - & - & - & - \\
\hline 13026 & 167 & - & - & - & - \\
\hline 17082 & 219 & - & - & - & - \\
\hline
\end{tabular}

(*denotes the highest peak pressure variation amplitude) 
If a monochromatic acoustic pulse is required, then a neck should be add to the Helmholtz cavity, to tolerate the acoustic impedance of the resonator and boost the pressure resonance at a certain frequency. In this case, equation 11 should applied instead of equation 12.

\section{Conclusion}

A few milliseconds width, high SPL harmonic acoustic impulses in the range of 60 to $110 \mathrm{~dB}$, has been generated from neckless Helmholtz resonators, by intra-cavity nanosecond LIP shockwaves. It was found that the generated SPL depends on the laser wavelength, the cavity diameter, the laser ablation threshold fluence of the cavity material, the plasma temperature, and the plasma pressure. Also, it was found that the frequency response of the cavities depending on the cavities diameter and laser wavelength. Hollow spheres resonators of different diameters made of AISI 316L stainless steel were subject to Q-switched Nd:YAG LIP at the principal, second, and third harmonic generation wavelength. Under constant laser fluence of $5 \mathrm{~J} / \mathrm{cm}^{2}$, an odd/even acoustic harmonic multiplicity dependence on laser wavelength was revealed. The SPL contour plot around the resonators seemed to be quasi-spherical due to the contribution of cavity breathing modes in sound generation. The dependence of Helmholtz harmonics on mode coupling phenomena is believed to be governing the acoustic frequency response. The LIBS analysis of the plasma spectrum estimated a plasma temperature in the order of $10^{5} \mathrm{~K}$ and a plasma pressure in the order of $10^{8} \mathrm{~Pa}$. The prospective application of this method is to append dodecahedron loudspeakers in some standard acoustic tests.

\section{References}

[1] Papadakis, Nikolaos M., and Georgios E. Stavroulakis. "Review of Acoustic Sources Alternatives to a Dodecahedron Speaker." Applied Sciences 9, no. 18 (2019): 3705.

[2] Fahy, Frank J. Foundations of engineering acoustics. Elsevier, 2000.

[3] Kuttruff, Heinrich. Room acoustics. CRC Press, 2016.

[4] Zhang, Jun-Jie, Liang Zhao, Andreas Rosenkranz, Cheng-Wei Song, Yong-Da Yan, and Tao Sun. "Nanosecond Pulsed Laser Ablation on Stainless Steel- Combining Finite Element Modeling and Experimental Work." Advanced engineering materials 21, no. 8 (2019): 1900193.

[5] Ayoub, H. S., Ashraf F. El-Sherif, Sana MA Maize, and Y. H. Elbashar. "Design and implementation of photoacoustic based beam dump-average optical power meter for fast and ultrafast lasers." Optics and Lasers in Engineering 140 (2021): 106548.

[6] Rossing, Thomas, ed. Springer handbook of acoustics. Springer Science \& Business Media, 2007.

[7] Arnela, Marc, Oriol Guasch, Patricia Sánchez-Martín, Joan Camps, Rosa Ma Alsina-Pagès, and Carme Martínez-Suquía. "Construction of an omnidirectional parametric loudspeaker consisting in a spherical distribution of ultrasound transducers." sensors 18, no. 12 (2018): 4317.

[8] Quested, Christopher, Andy Moorhouse, Ben Piper, and Bin Hu. "An analytical model for a dodecahedron loudspeaker applied to the design of omni-directional loudspeaker arrays." Applied acoustics 85 (2014): 161-171.

[9] Hosoya, Naoki, Masaki Nagata, and Itsuro Kajiwara. "Acoustic testing in a very small space based on a point sound source generated by laser-induced breakdown: Stabilization of plasma formation." Journal of Sound and Vibration 332, no. 19 (2013): 4572-4583.

[10] Stafe, Mihai, C. Negutu, Niculae N. Puscas, and I. M. Popescu. "Pulsed laser ablation of solids." Rom. Rep. Phys 62, no. 4 (2010): 758-770.

[11] Cabalin, L. M., and J. J. Laserna. "Experimental determination of laser induced breakdown thresholds of metals under nanosecond Q-switched laser operation." Spectrochimica Acta Part B: Atomic Spectroscopy 53, no. 5 (1998): 723-730.

[12] Sound Power Measurements, Hewlett Packard Application Note 1230, 1992.

[13] Greene, Chad A.; Argo IV, Theodore F.; Wilson, Preston S. "A Helmholtz resonator experiment for the Listen Up project". Proceedings of Meetings on Acoustics ASA: 025001. (2009). doi:10.1121/1.3112687

[14] Wolfe, Joe. "Helmholtz resonance." School of Physics at UNSW: Sydney, Australia (2000).

[15] Raichel, Daniel R. The science and applications of acoustics. Springer Science \& Business Media, (2006). 
[16] Stainless Steels Grade Datasheets, Atlas Steels Technical Department, August (2013), www.atlassteels.com.au.

[17] Redmond, R. F., and J. Lones. Enthalpies and heat capacities of stainless steel (316), zirconium, and lithium at elevated temperatures. No. ORNL-1342. Oak Ridge National Lab., 1952.

[18] Pichler, Peter, Brian J. Simonds, Jeffrey W. Sowards, and Gernot Pottlacher. "Measurements of thermophysical properties of solid and liquid NIST SRM 316L stainless steel." Journal of Materials Science 55, no. 9 (2020): 4081-4093.

[19] Kim, Choong S. Thermophysical properties of stainless steels. No. ANL- $\underline{75-55}$. Argonne National Lab., Ill.(USA), 1975.

[20] Mościcki, T., Jacek Hoffman, and Z. Szymański. "Modelling of plasma formation during nanosecond laser ablation." Archives of Mechanics 63, no. 2 (2011): 99-116.

[21] Gornushkin, Igor B., Sergej V. Shabanov, Sven Merk, E. Tognoni, and Ulrich Panne. "Effects of non-uniformity of laser induced plasma on plasma temperature and concentrations determined by the Boltzmann plot method: implications from plasma modeling." Journal of Analytical Atomic Spectrometry 25, no. 10 (2010): 1643-1653.

[22] Hussain, T., M. A. Gondal, and M. Shamraiz. "Determination of plasma temperature and electron density of iron in iron slag samples using laser induced breakdown spectroscopy." In IOP Conference Series: Materials Science and Engineering, vol. 146, no. 1, p. 012017. IOP Publishing, 2016.

[23] Kramida, A., K. Olsen, and Yu Ralchenko. "Nist libs database." National Institute of Standards and Technology, US Department of Commerce (2019). 


\section{Figures}
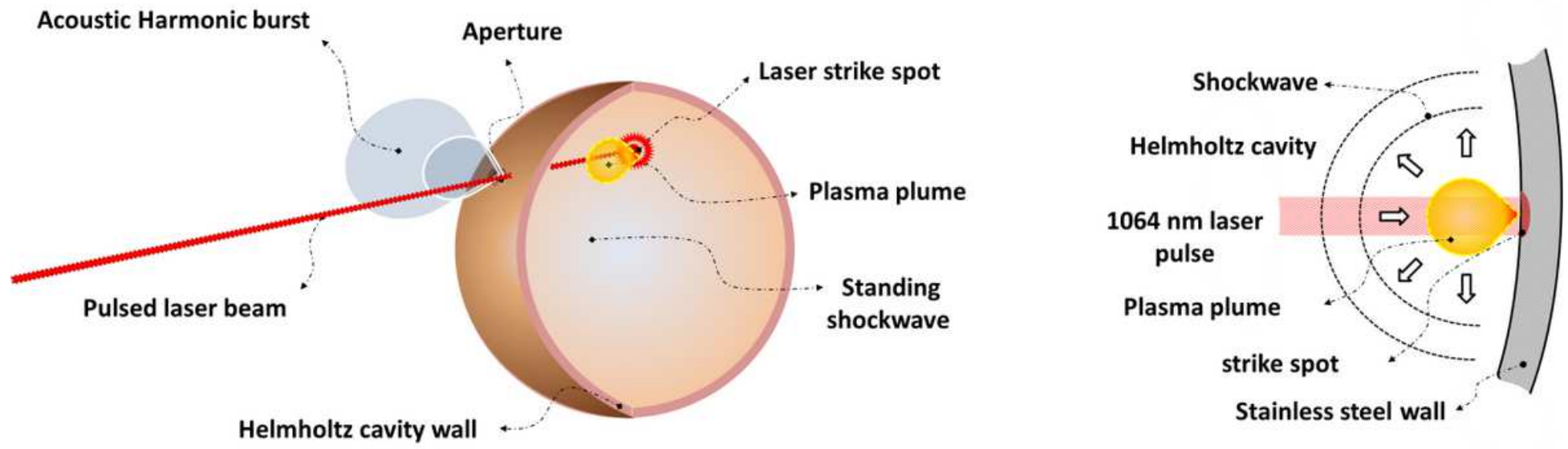

\section{Figure 1}

Illustration of the laser induced plasma Helmholtz resonator: (a) An imaginary section in the resonator showing the laser strike spot and the plasma plume shockwave (b) Plasma Plume formation

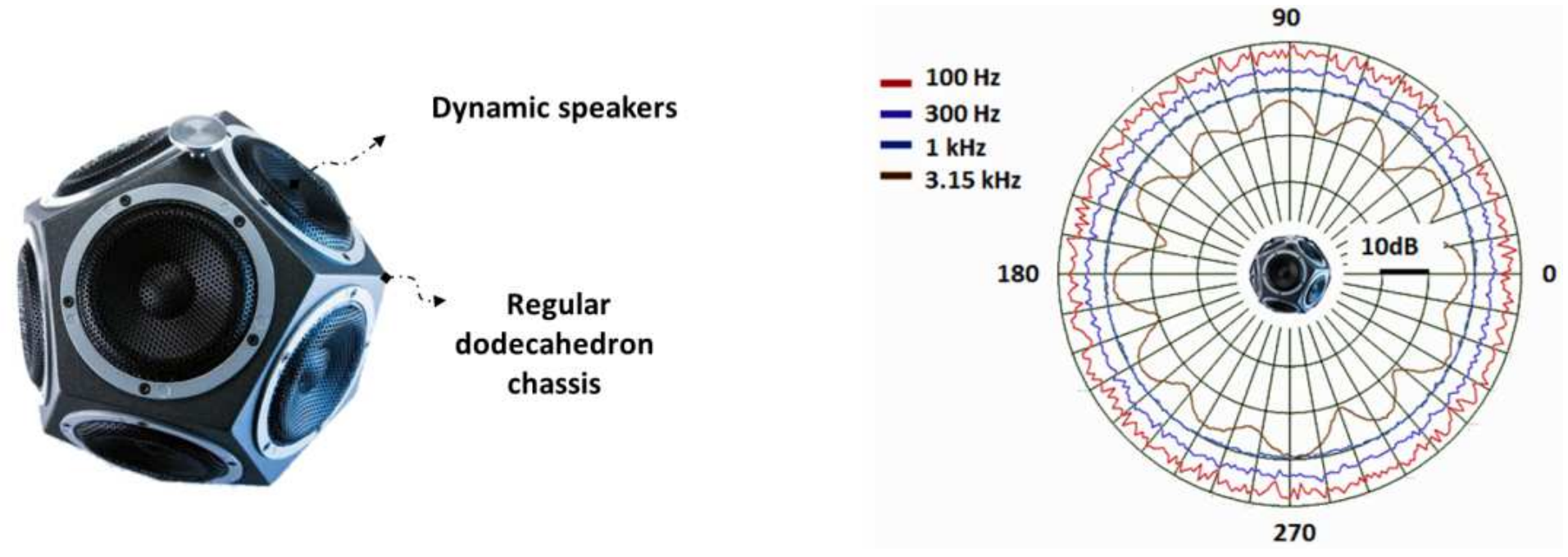

Figure 2

Typical dodecahedron loudspeaker (a) assembly (b) sound field polar plot
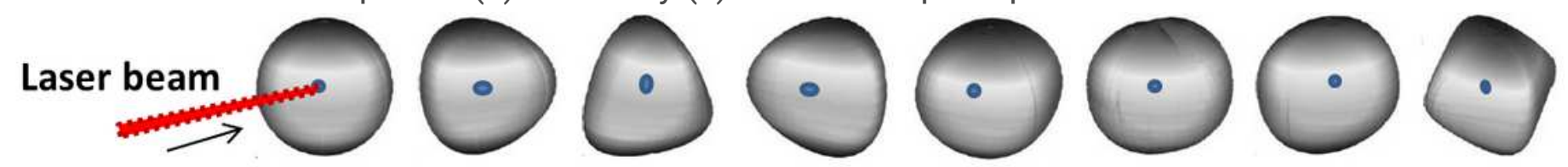

Figure 3

Illustration of cavity breathing modes as a result of an intense laser thermoelastic impulse 

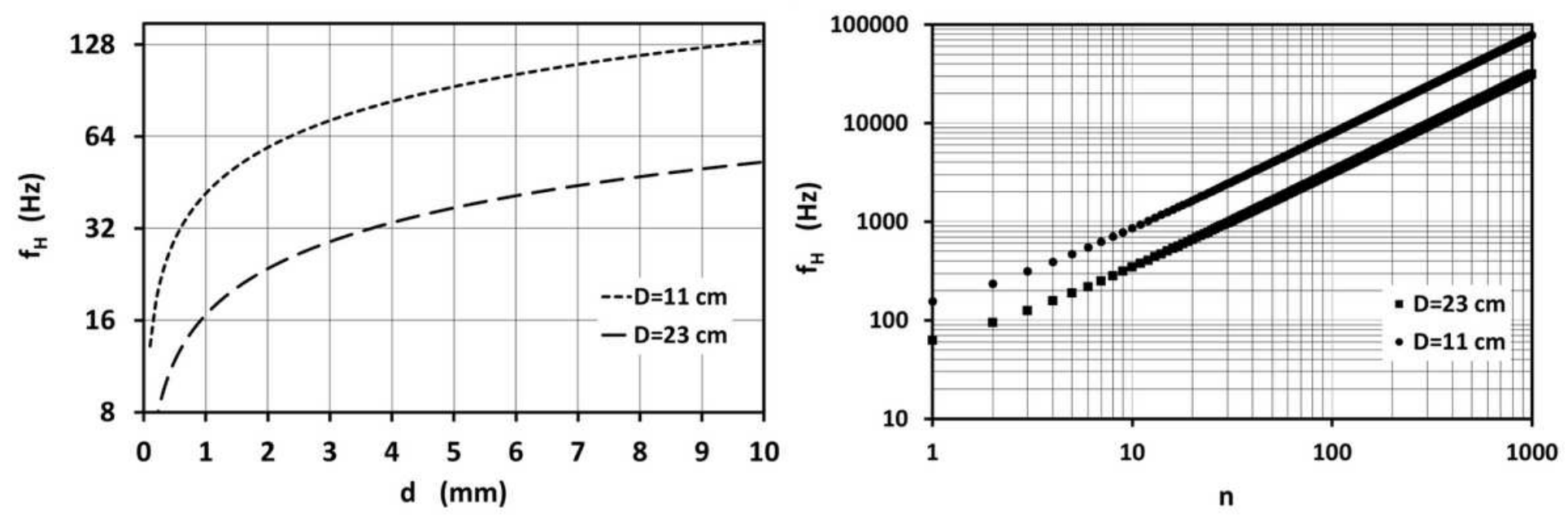

Figure 4

Effect of sphere diameter on Helmholtz resonance (a) as function of hole diameter (b) as function of multiplicity.
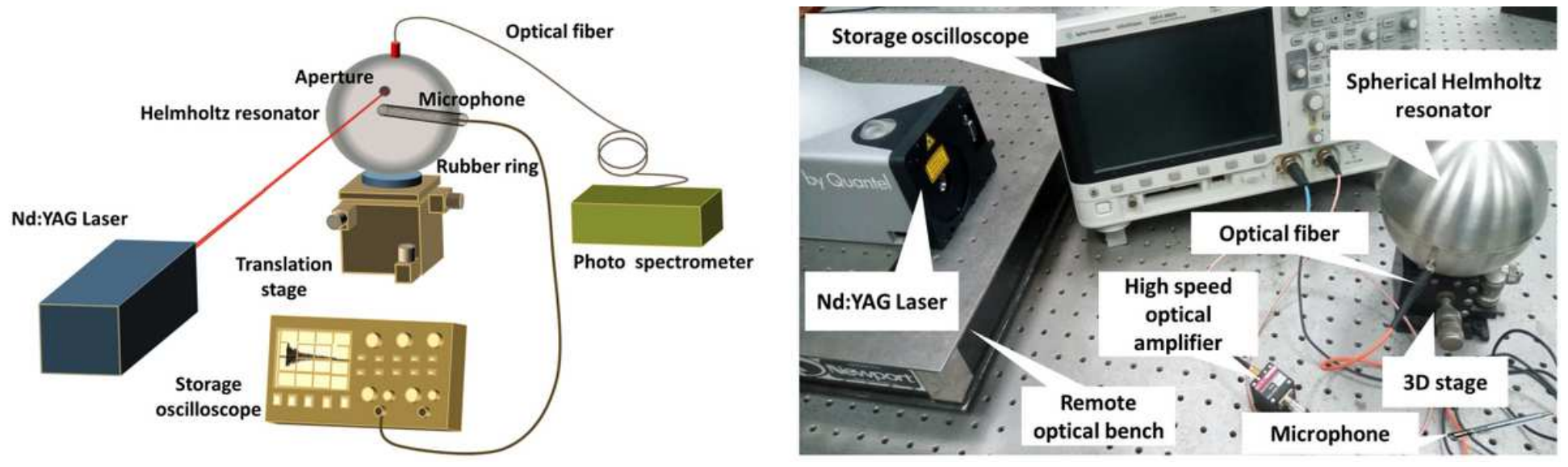

Figure 5

Measurement setup (a) Illustration of the system (b) Experimental setup

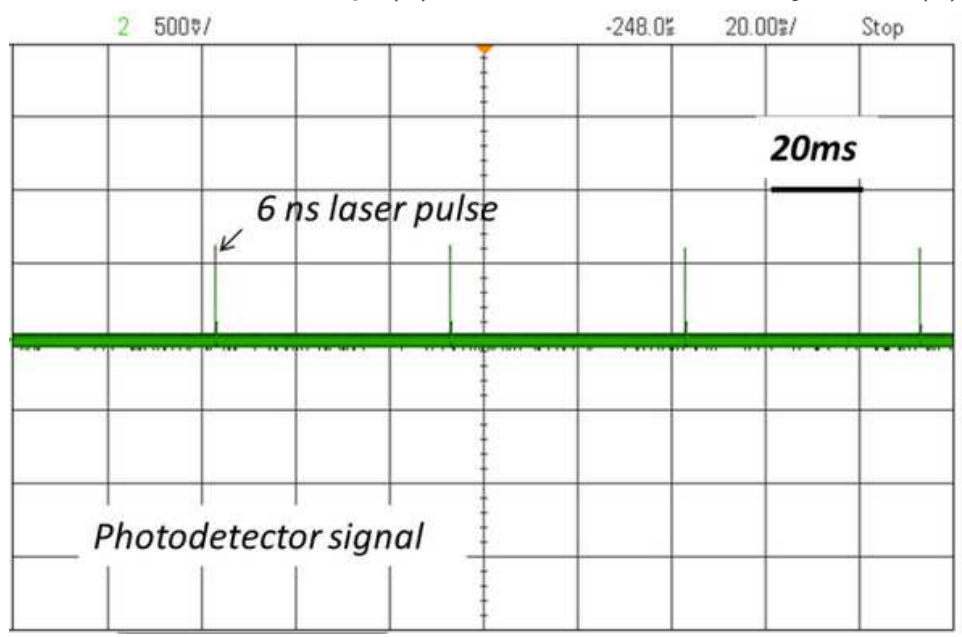

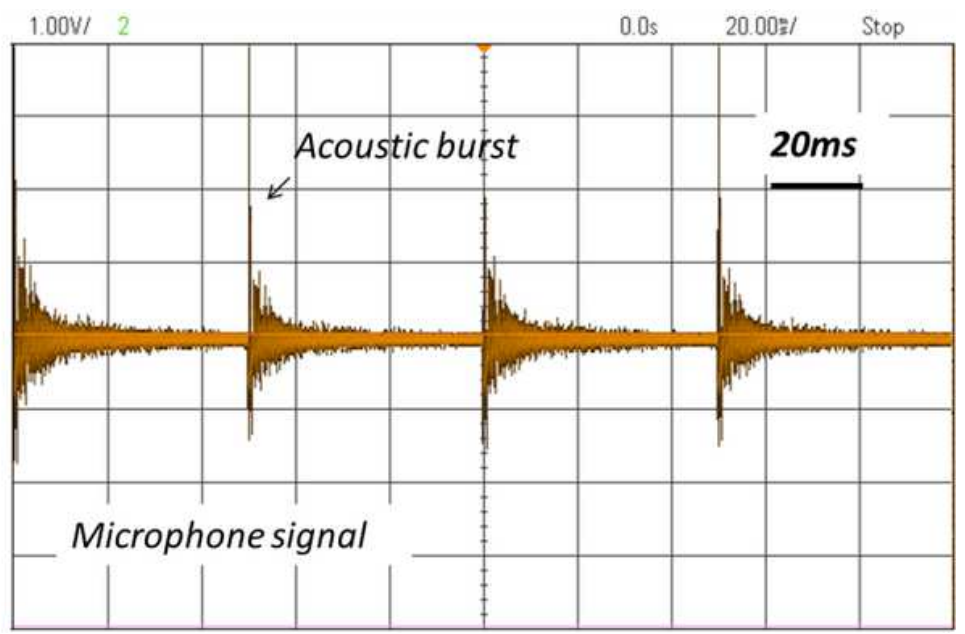

Figure 6 
$20 \mathrm{~Hz}$ pulse train of (a) $1064 \mathrm{~nm}, 6 \mathrm{~ns} \mathrm{Nd}$ :YAG laser irradiating the inner surface of a $23 \mathrm{~cm}$ diameter Helmholtz cavity at $5 \mathrm{~J} / \mathrm{cm} 2$ fluence (b) acoustic burst of standing Helmholtz pressure wave at the cavity entrance hole.
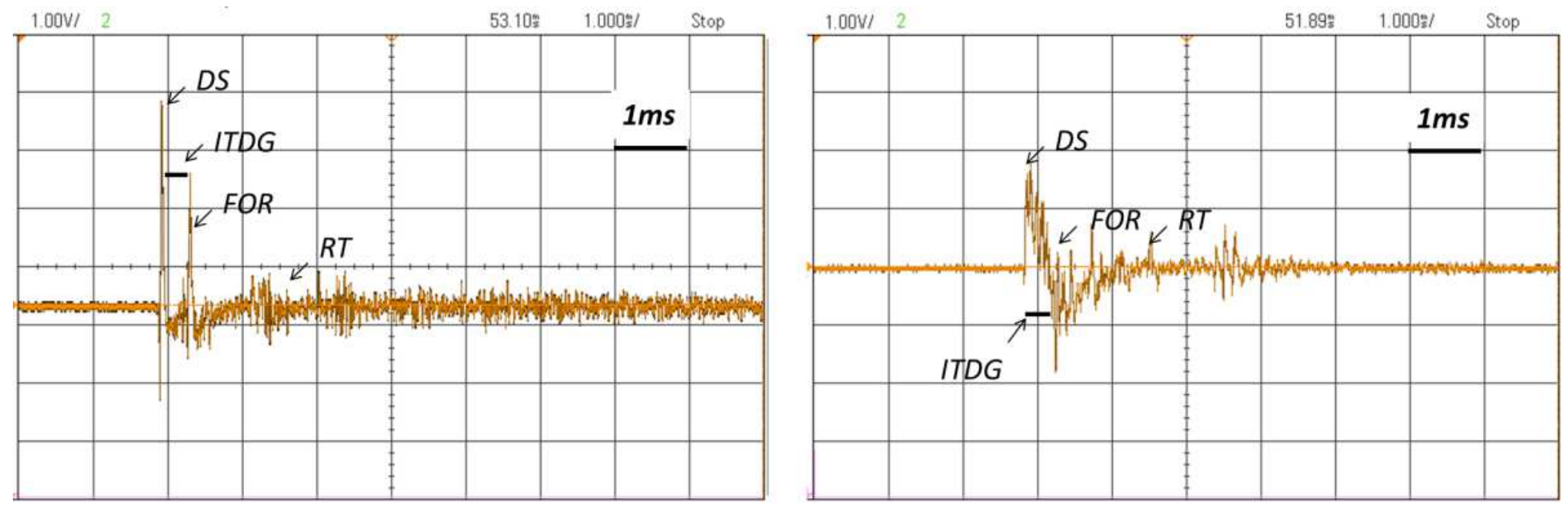

Figure 7

Impulse response of the Helmholtz cavities for (a) $D=23 \mathrm{~cm}$ (b) $D=11 \mathrm{~cm}$.
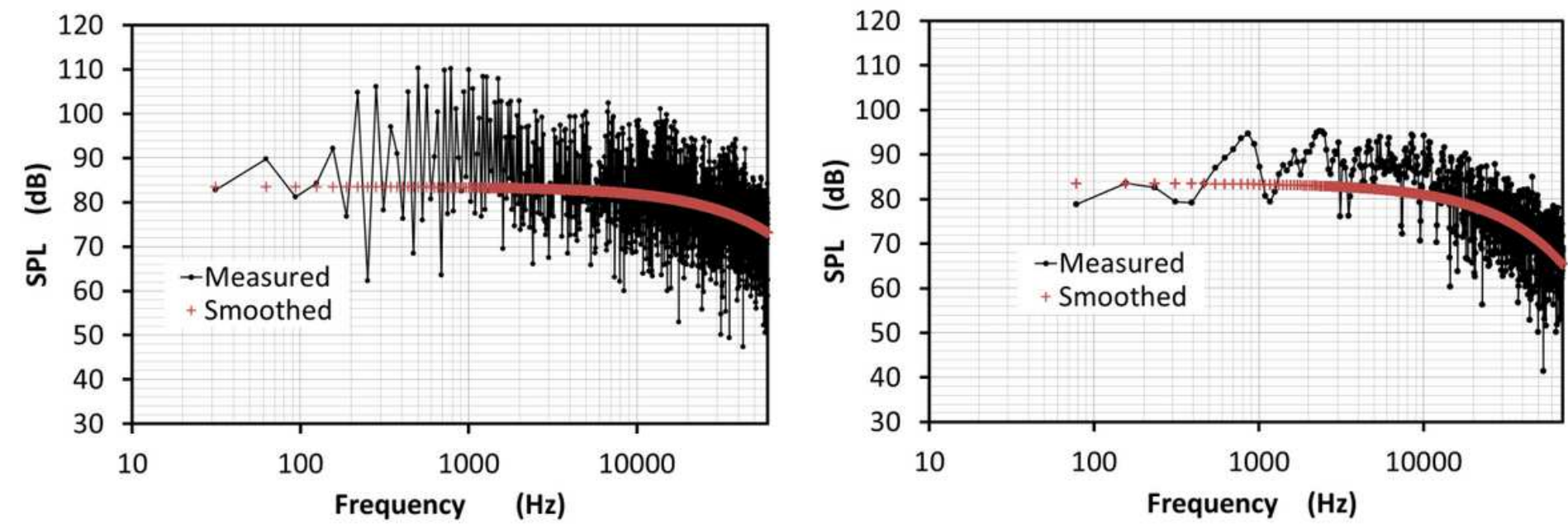

Figure 8

Frequency response of Helmholtz cavities of (a) $D=23 \mathrm{~cm}$ (b) $D=11 \mathrm{~cm}$ 

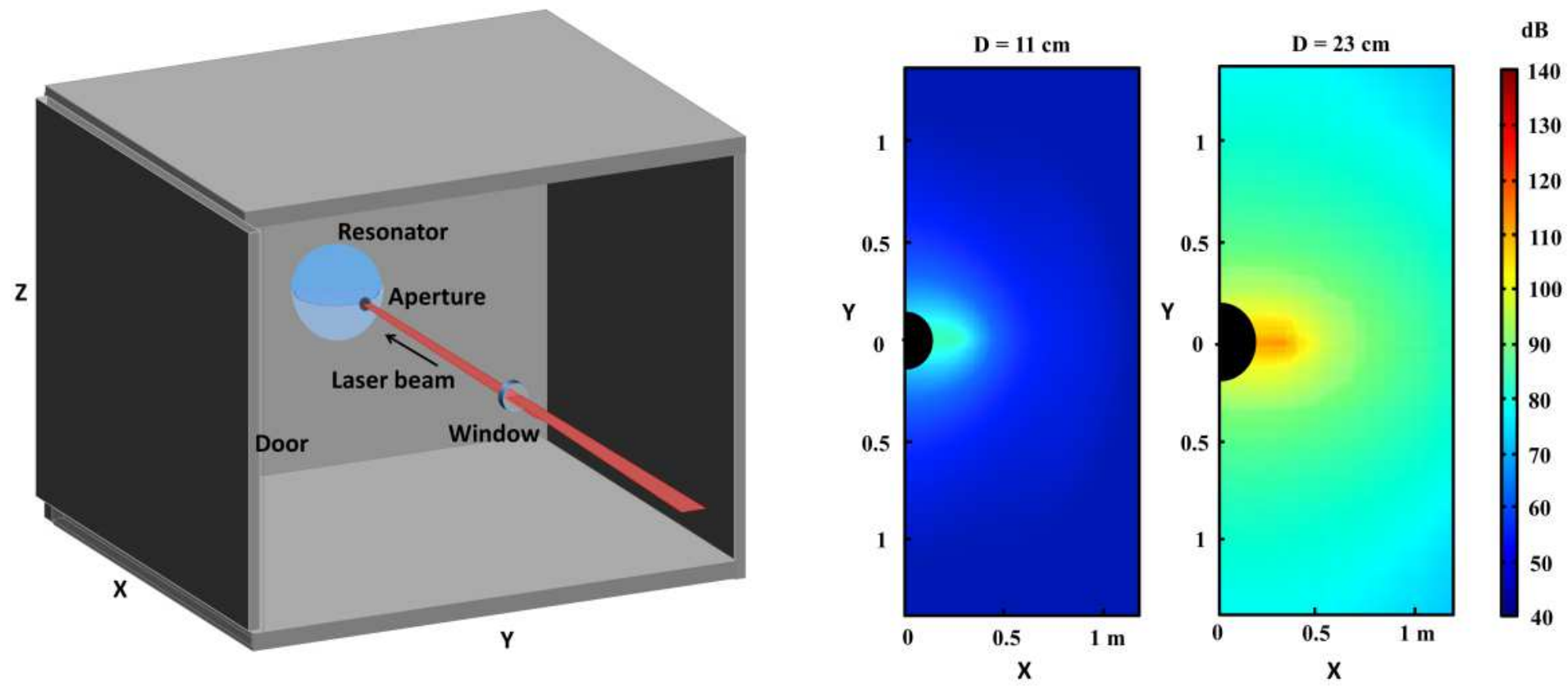

Figure 9

SPL field measurements (a) illustrative section in the anechoic chamber (b) the average SPL contour plot for both resonators using principal Nd:YAG laser wavelength at $F=2 \mathrm{~J} / \mathrm{cm} 2$.
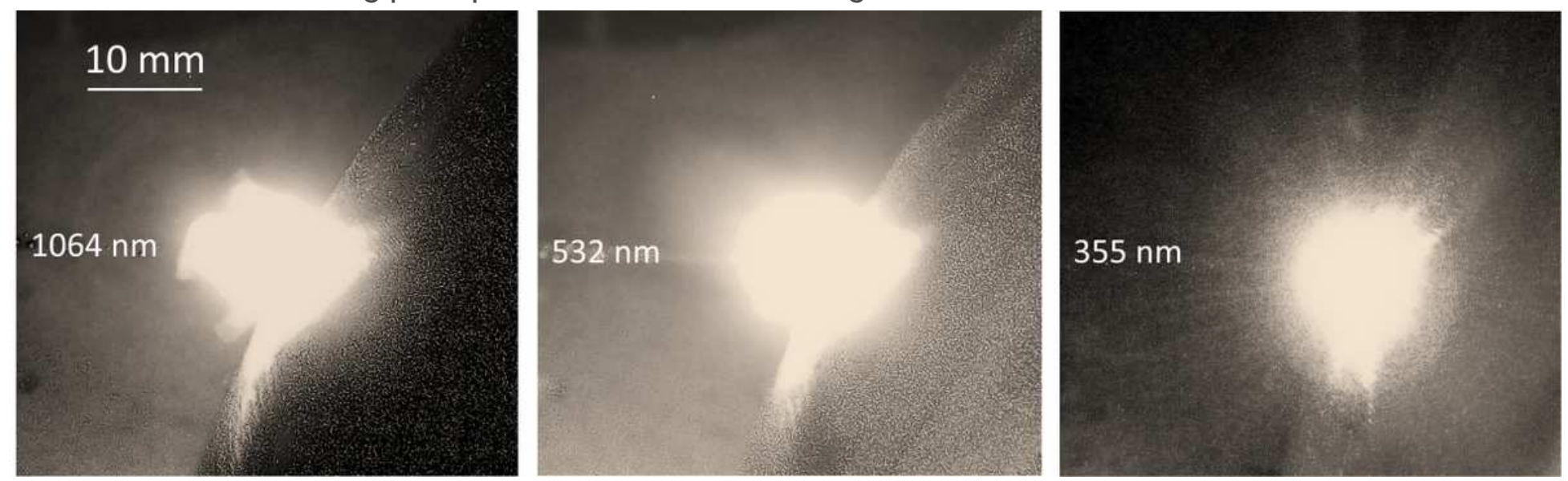

\section{Figure 10}

LIP visible emission from spherical stainless steel surface at atmospheric pressure with synchronized delay of $0.3 \mathrm{~ms}$, frame rate of $75 \mathrm{fps}$, laser fluence of $5 \mathrm{~J} / \mathrm{cm} 2$ and wavelength of (a) $1064 \mathrm{~nm}$ (b) 532 $\mathrm{nm}$ (c) $355 \mathrm{~nm}$. 


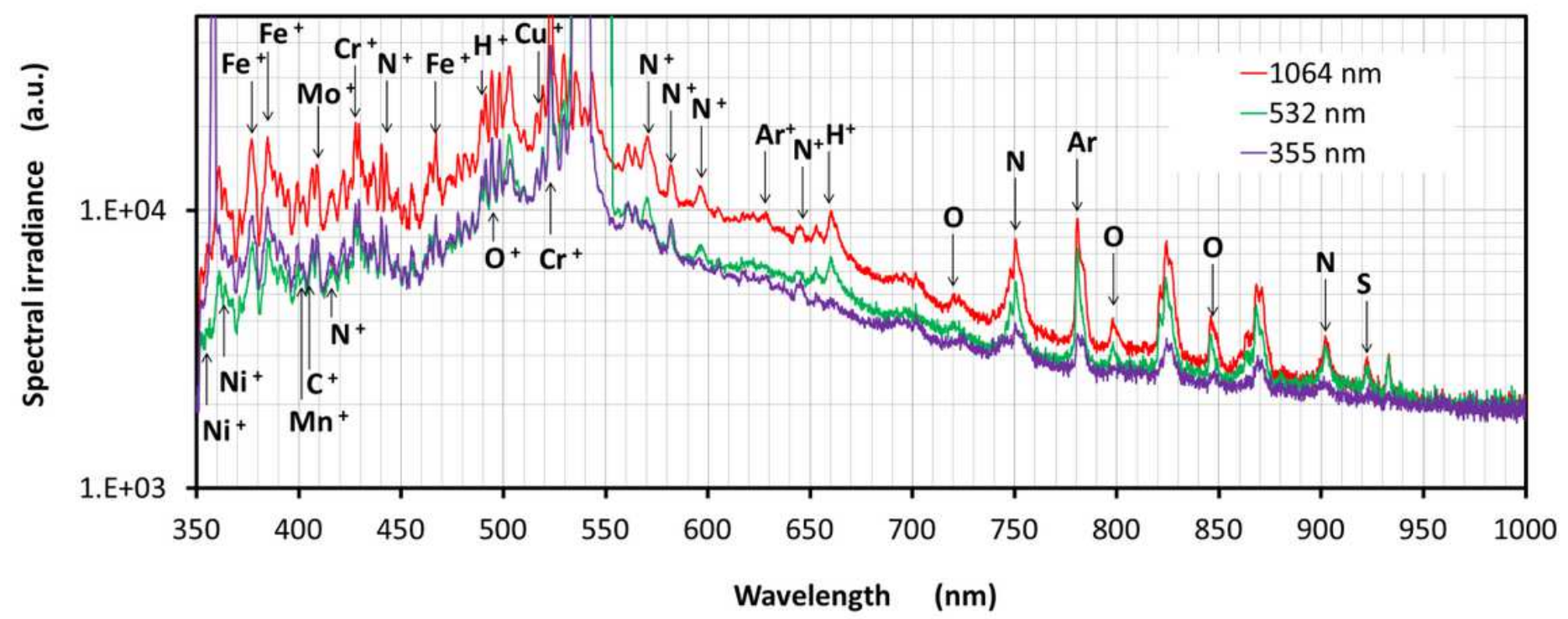

Figure 11

Broad band VIS/NIR plasma spectral irradiance of AISI 316 stainless steel, at distance of $0.05 \mathrm{~mm}$, induced by principal, second and third harmonic generation wavelengths of Q-switched Nd:YAG laser, at $\mathrm{F}=5 \mathrm{~J} / \mathrm{cm} 2$.

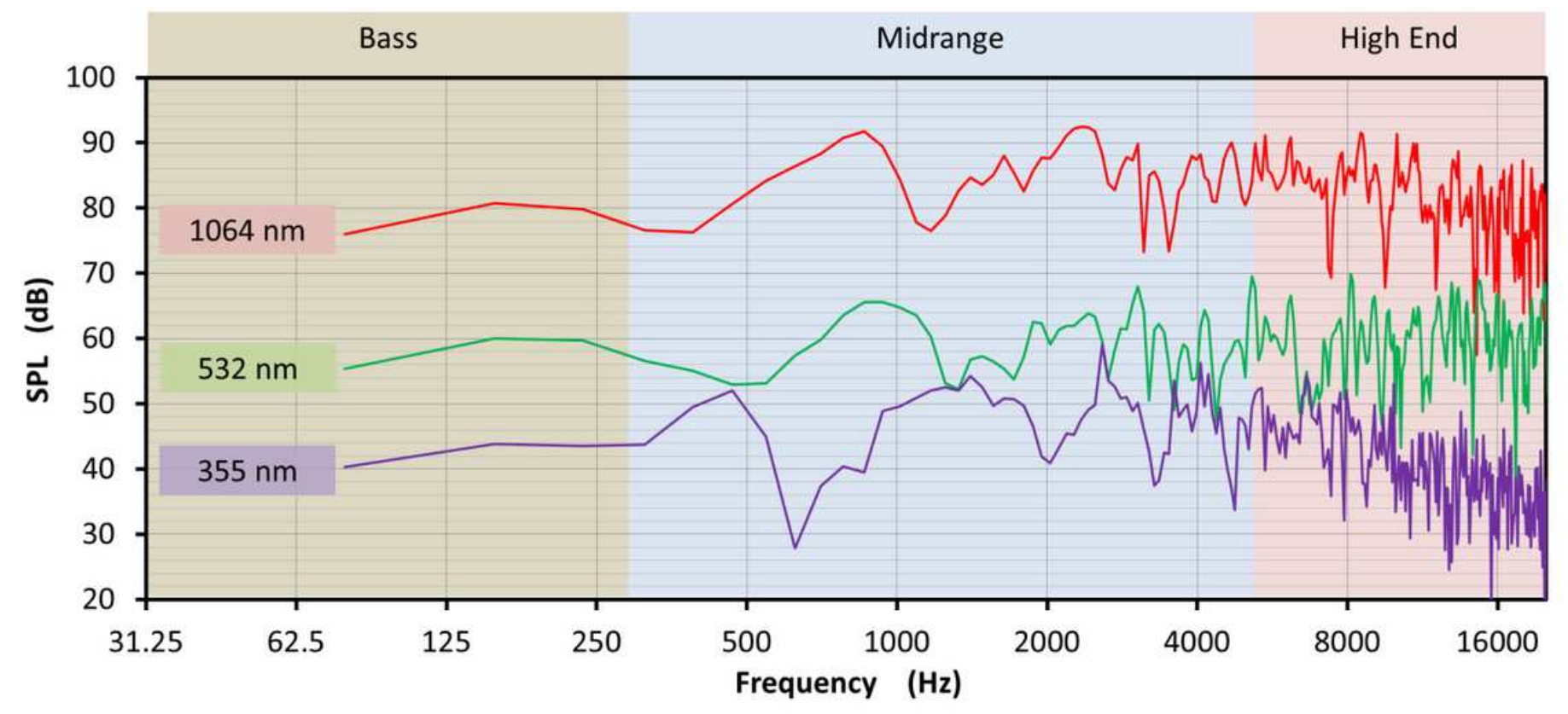

Figure 12

Octave band response of Helmholtz cavity $D=11 \mathrm{~cm}$ induced by principal, second and third harmonic wavelengths of Q-switched Nd:YAG at F=5J/cm2. 